\title{
Dust aerosols over India and adjacent continents retrieved using METEOSAT infrared radiance Part I: sources and regional distribution
}

\author{
S. Deepshikha, S. K. Satheesh, and J. Srinivasan \\ Centre for Atmospheric and Oceanic Sciences, Indian Institute of Science, Bangalore-560 012, India
}

Received: 20 January 2005 - Revised: 2 December 2005 - Accepted: 21 December 2005 - Published: 7 March 2006

\begin{abstract}
Mineral dust constitutes the single largest contributor to continental aerosols. To accurately assess the impact of dust aerosols on climate, the spatial and temporal distribution of dust radiative properties is essential. Regional characteristics of dust radiative properties, however, are poorly understood. The magnitude and even sign of dust radiative forcing is uncertain, as it depends on a number of parameters, such as vertical distribution of dust, cloud cover and albedo of the underlying surface. In this paper, infrared radiance $(10.5-12.5 \mu \mathrm{m})$, acquired from the METEOSAT-5 satellite $(\sim 5-\mathrm{km}$ resolution), was used to retrieve regional characteristics of dust aerosols for all of 1999. The infrared radiance depression, due to the presence of dust in the atmosphere, has been used as an index of dust load, known as the Infrared Difference Dust Index (IDDI). There have been several studies in the past carried out over the Sahara using IDDI as a measure of dust load. Over the Indian region, however, studies on dust aerosols are sparse. Spatial and temporal variability in dust loading and its regional distribution over various arid and semiarid regions of India and adjacent continents $\left(0-35^{\circ} \mathrm{N} ; 30^{\circ} \mathrm{E}-100^{\circ} \mathrm{E}\right)$ (excluding Sahara) have been studied and the results are examined along with surface soil conditions (such as vegetation cover and soil moisture). The advantage of the IDDI method is that information on aerosol properties, such as chemical composition or microphysical properties, is not needed. A large day-to-day variation in IDDI was observed over the entire study region, with values ranging from 4 to $22 \mathrm{~K}$. It was observed that dust activity starts by March over the Indian deserts, as well as over deserts of the Africa and Arabian regions. The IDDI reaches maximum during the period of May to August. Regional maps of IDDI, in conjunction with biomass burning episodes (using TERRA satellite fire pixel counts), suggest that large IDDI values observed during the winter months over Northern India could be due to a possible deposition of black carbon on larger dust aerosols. The IDDI values have been
\end{abstract}

Correspondence to: S. K. Satheesh

(satheesh@ caos.iisc.ernet.in) compared with another year (i.e. 2003), with a large number of dust storms reported by meteorological departments based on visibility data. During the dry season, the magnitude of the monthly average IDDI during 2003 was slightly higher than that of 1999 . The monthly mean IDDI was in the range from 4 to $9 \mathrm{~K}$ over the Indian deserts, as well as over the deserts of Africa and Arabia. The maximum IDDI during a month was in the range from 6 to $18 \mathrm{~K}$. Large IDDI values were observed even over vegetated regions (such as the vegetated part of Africa and central India), attributed to the presence of transported dust from nearby deserts.

Keywords. Atmospheric composition and structure (Aerosols and particles; Transmission and scattering of radiation) - History of Geophysics (Atmospheric sciences)

\section{Introduction}

Soil derived particles are among the largest aerosols with radii ranging from less than $0.1 \mu \mathrm{m}$ to $\sim 100 \mu \mathrm{m}$ (Prospero et al., 1983, 2002; Kaufman et al., 1995; Haywood and Boucher, 2000; Kaufman et al., 2002; Seinfeld et al., 2004). Large particles are present mainly in the source regions but particles in the radius range $0.1-5.0 \mu \mathrm{m}$ (or even larger) are transported to long distances $(\sim 5000 \mathrm{kms})$ in the marine atmosphere (Junge, 1972; Kalu, 1979; Arimoto et al., 1995, 1997; Prospero, 2001, 2003; Satheesh and Srinivasan, 2002; Gong et al., 2003; Prospero and Lamb, 2003; Petit et al., 2005). For example, several investigations over the Atlantic Ocean have observed Saharan dust, even at remote locations in the Atlantic Ocean (Moulin et al., 1998; Prospero et al., 2002; Seinfeld et al., 2004). The measurements of aerosol size distribution and analysis of chemical composition of aerosols over Antarctica have found mineral particles with radii greater than $2 \mu \mathrm{m}$ of Australian origin (Shaw, 1980; Shaw et al., 1998). Since composition of the soil varies locally, the mineral aerosols derived from soil exhibit high variability in their imaginary part of the refractive index that 
mainly determines the climate forcing by this type of aerosol (Zender et al., 2003; Ginoux et al., 2001, 2004; Seinfeld et al., 2004; Tegen et al., 2004). The efficiency with which aerosols are produced from deserts varies depending on the soil characteristics at the particular location (Gillette, 1979).

By its omnipresence, the desert aerosol can have a significant impact on the atmospheric radiation (Sokolik et al., 1998; Arimoto, 2001; Tegen et al., 2004). Dust not only scatters but also absorbs solar radiation and also absorbs and emits long wave radiation (Haywood and Boucher, 2000; Satheesh and Ramanathan, 2000). The magnitude and even the sign of direct radiative forcing by dust is uncertain (IPCC, 2001; Seinfeld et al., 2004; Tegen et al., 2004). It depends on a number of parameters, such as the optical properties of dust, its vertical distribution, cloud cover and the albedo of the underlying surface (Heintzenberg et al., 1997; Liao and Seinfeld, 1998; Tanré et al., 2001, 2003). Dust aerosols are significant contributors to radiative warming below $500 \mathrm{mb}$ due to short wave absorption (Chen et al., 1995; Mohalfi et al., 1998; Alpert et al., 1998; Miller and Tegen, 1999; Prospero, 2003; Prospero and Lamb, 2003). Typically, dust approximately doubles the short wave radiation absorption under clear-sky conditions (Tegen and Miller, 1998; Tanré et al., 2003). Tegen and Fung (1994) have shown that dust from disturbed soil causes a net cooling at the surface, accompanied by an increase in atmospheric heating. Such radiative effects are found to be most pronounced over the desert regions (Mohalfi et al., 1998; Haywood et al., 2001, 2003; Tanré et al., 2001; Zhang and Christopher, 2003).

\section{Problems in quantification of dust}

There are some difficulties involved in remote sensing (using visible wavelengths) of dust over land (Kaufman et al., 1997). Continuous in-situ sampling of dust aerosol is not feasible over desert regions, due to logistical reasons, and hence the number of sites, which can be maintained is limited (Holben et al., 1998). Remote sensing using visible wavelengths is complicated due to high and varying albedo over the desert, where high dust load is present. Recently, Hsu et al. (2004) has demonstrated that aerosol optical depths can be derived using MODIS data over bright surfaces. Martonchik et al. (2004) has compared MISR derived optical depths with those measured by AERONET sites over the deserts and found good agreement. Dust aerosols are, however, known to be non-spherical in shape. This can cause errors in the remote sensing of dust aerosols from visible wavelengths.

Recent investigations as part of Aerosol Characterization Experiment-Asia (ACE-Asia) have shown that the dust we observe may not be just dust, but it may be dust mixed with other aerosols (Seinfeld et al., 2004). Studies by Parungo et al. (1987) demonstrate that dust particles originating from China's desert are coated by sulfates or soot after passing through polluted industrial regions downwind of the desert and in contrast, Saharan dust transported over the Atlantic Ocean is often coated by sea salt. Dust particles internally mixed with soot, sulfates, nitrates or aqueous solutions can have drastically different properties from those at the dust source (Jacobson, 2001; Chandra et al., 2004; Deepshikha et al., 2005). The dust that is transported from East Asia to the Pacific does not absorb as much radiation as the dust from South Asia or the dust from the Sahara Desert (Seinfeld et al., 2004). There are dramatic regional differences in the chemical and optical properties of aerosols (Zender et al., 2003; Ginoux et al., 2004). Part of the complexity in estimating dust radiative impact arises from the fact that dust sources and sinks are not uniformly distributed (Sokolik et al., 1998; Tegen et al., 2004). Consequently, the dust aerosol has a complex spatial and temporal pattern.

Recent experiments have shown that measurements of dust at various locations alone cannot provide information on its transport and consequent impact over other regions (Seinfeld et al., 2004). To accurately assess the impact of dust aerosols on climate, the spatial and temporal distribution of dust is essential. However, regional characteristics of soil dust production, and transport and removal processes are less understood. Retrieval methods using infrared wavelengths (a technique used in this paper) have proved to be more suitable for studies on dust aerosols (Tanré and Legrand, 1991; Legrand et al., 2001; Leon and Legrand, 2003). Using NIMBUS data, Shenk and Curran (1974) have demonstrated that dust can be detected over arid regions using infrared radiance. Subsequently, Legrand et al. (1983, 1985), using METEOSAT infrared radiance data, studied dust aerosols over North Africa and Arabia. The studies carried out thereafter have demonstrated the potential of infrared radiance for quantitative estimates of dust aerosols (Ackerman, 1989; Legrand et al., 1989, 1992, 1994, 2001; Tanré and Legrand, 1991; Leon and Legrand, 2003).

In this paper, infrared radiance $(10.5-12.5 \mu \mathrm{m})$ from the METEOSAT-5 satellite (of European Space Agency ESA -) has been used ( $\sim 5-\mathrm{km}$ resolution) to retrieve dust aerosol characteristics. During the Indian Ocean Experiment (INDOEX), METEOSAT-5 was moved to $66^{\circ} \mathrm{E}$ and provided an excellent opportunity to study dust aerosols over India and adjacent continents. The principle behind the retrieval technique is based on the fact that the presence of dust aerosols reduces the infrared radiance detected by the satellite. The radiance depression resulting from the presence of dust in the atmosphere has been used as an index of dust load and is called the Infrared Difference Dust Index (IDDI) (Tanré and Legrand, 1991; Legrand et al., 2001). The raw data from METEOSAT (in the form of radiance counts) is converted to InfraRed Brightness Temperature (IRBT), using an inverse Plank Function. The IDDI images were created from IRBT images to study the regional characteristics of dust following Legrand et al. (2001). The variability of atmospheric dust loading over arid and semiarid regions of India and adjacent continents, such as regions of Africa (excluding Sahara) and Arabia, has been studied. 
Table 1. Properties of various aerosol components.

\begin{tabular}{|l|l|l|l|l|}
\hline Aerosol Component & $\mathrm{r}_{\mathrm{m}}, \mu \mathrm{m}$ & $\sigma$ & $\rho, \mathrm{g} \mathrm{cm}^{-3}$ & $\omega(500 \mathrm{~nm})$ \\
\hline $\begin{array}{l}\text { Water soluble } \\
\text { (sulphate, nitrate etc) }\end{array}$ & 0.029 & 2.24 & 1.8 & 0.99 \\
\hline Soot & 0.018 & 2.0 & 1.0 & 0.23 \\
\hline Sea-salt (accum. mode) & 0.378 & 2.03 & 2.2 & 1.0 \\
\hline Sea-salt (coarse mode) & 3.17 & 2.03 & 2.2 & 1.0 \\
\hline Mineral dust & 0.50 & 2.0 & 2.6 & 0.97 \\
\hline
\end{tabular}

\section{Detection of dust using infrared radiance: data and analysis}

As the dust aerosol load (often represented by dust optical depth) increases, there is a consequent reduction in short wave solar radiation reaching the surface. This is due to the combined effect of scattering and absorption. Similarly, there is a reduction in the Outgoing Long Wave radiation (OLW) at the top of the atmosphere (TOA) because of the absorption due to dust. When the dust aerosol optical depth increases from zero to 1.0 , the consequent reduction in OLR is around $30 \mathrm{~W} \mathrm{~m}^{-2}$ (Satheesh et al., 2005). Here, the desert aerosol model described in Hess et al. (1998) and Kaufman et al. (2001) was used to estimate the radiative impact of dust to long wave radiation.

To examine the impact of dust aerosols and other aerosol species on infrared radiation, sensitivity analysis has been carried out. Here, a four-component aerosol system, consisting of mineral dust, sea salt, soot and sulphate, was considered. The optical properties of different aerosol species are obtained from Hess et al. (1998) and Kaufman et al. (2001). The physical properties, such as mode radii $\left(\mathrm{r}_{m}\right)$, standard deviation $(\sigma)$ and density $(\rho)$, and optical properties, such as single scattering albedo $(\omega)$ of the individual aerosol components, are shown in Table 1. We have shown in Fig. 1 the optical depth at $0.5 \mu \mathrm{m}$ and $11 \mu \mathrm{m}$, due to various aerosol species. When the dust optical depth at $0.5 \mu \mathrm{m}$ is 1.0 , the dust optical depth in IR (at $11 \mu \mathrm{m}$ ) is around 0.33 , which is higher than all other species. The second highest contributor to infrared optical depth is sea salt, which has an optical depth of 0.06 at $11 \mu \mathrm{m}$, which is much lower compared to dust optical depth. Sulphate and soot have much lower optical depths at $11 \mu \mathrm{m}$. This demonstrates that the mineral dust is the only aerosol species over land regions, which can influence the infrared radiation significantly. Over ocean, sea salt (though the effect is an order of magnitude smaller than dust) also contributes to the reduction in OLR. Aerosol optical depths measured over India are typically in the range from 0.2 to 0.7 , and the black carbon mass fraction is in the range of 10 to $15 \%$ (Moorthy et al., 2005). The black carbon mass concentration during daytime is typically $2 \mu \mathrm{g} \mathrm{m}^{-3}$ over Southern India and $6 \mu \mathrm{g} \mathrm{m}^{-3}$ over Northern India (Tripathi et al., 2005).

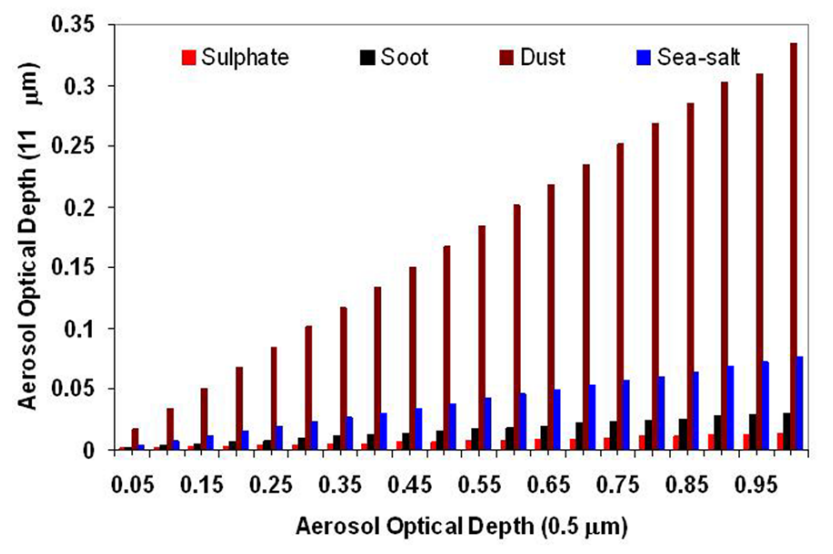

Fig. 1. Influence of various types of aerosols to infrared radiation, demonstrating that dust aerosols are the most sensitive to infrared.

Mineral dust particles constitute the largest aerosols over land. Large dust particles (i.e. of the order of 0.1 to $10 \mu \mathrm{m}$ in size) reduce IR radiance at the TOA, due to the combined effects of scattering and absorption (Legrand et al., 2001). Smaller particles (radius $<0.1 \mu \mathrm{m}$ ) will have a lesser effect on the OLR. This means sub-micron particles are mostly transparent in the infrared (Maley, 1982).

The radiance depression (with respect to clear-sky IR radiance), resulting from the presence of mineral dust aerosols in the atmosphere, can be used as an index of dust aerosol load (Tanré and Legrand, 1991). Dust layer reduces the infrared radiance received by satellites (Tanré and Legrand, 1991). Different processes involved in lowering the infrared radiance, due to dust, are discussed in the literature (Tanré and Legrand, 1991; Brooks, 2000; Legrand et al., 2001; Leon and Legrand, 2003) and are briefly outlined here.

- (a) The dust layer reduces (by scattering and absorption) incoming solar radiation and cools the land surface, thus reduces OLR.

- (b) The dust layer absorbs part of the OLR.

- (c) Some of this IR radiation absorbed in the dust layer will be converted to kinetic energy as the layer is heated and part will be re-emitted in all the directions, with only a fraction escaping to space.

In the present study, satellite measured infrared (IR) radiance acquired from METEOSAT-5 in the 10.5 to $12.5 \mu \mathrm{m}$ wavelength band (at $\sim 5-\mathrm{km}$ resolution) was used to retrieve dust aerosol properties. The approach is based on Tanré and Legrand (1991) and Legrand et al. (1994, 2001).

An IRBT depression, caused by the presence of dust aerosols in the atmosphere, can be used as an index of dust load and is called IDDI (Tanré and Legrand, 1991).

The radiance depression at the TOA, due to the presence of a dust laye, is,

$\Delta \mathrm{R}=\mathrm{R}_{\mathrm{t}}^{\uparrow}-\mathrm{R}_{\mathrm{b}}^{\uparrow}$ 

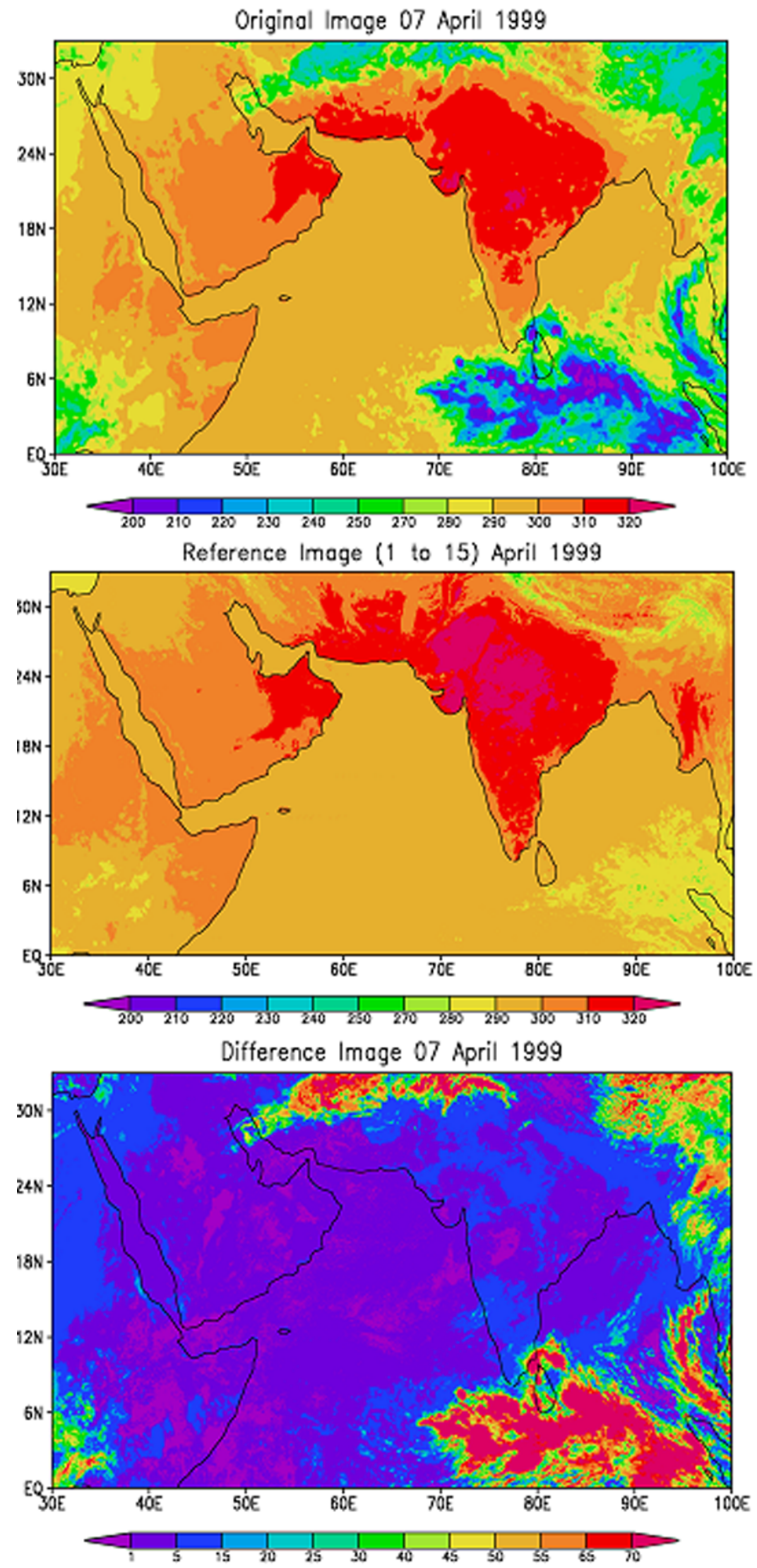

Fig. 2. (a) An example of an original IRBT image, (b) reference image for first 15 days of April 1999, (c) an example of a difference image. 

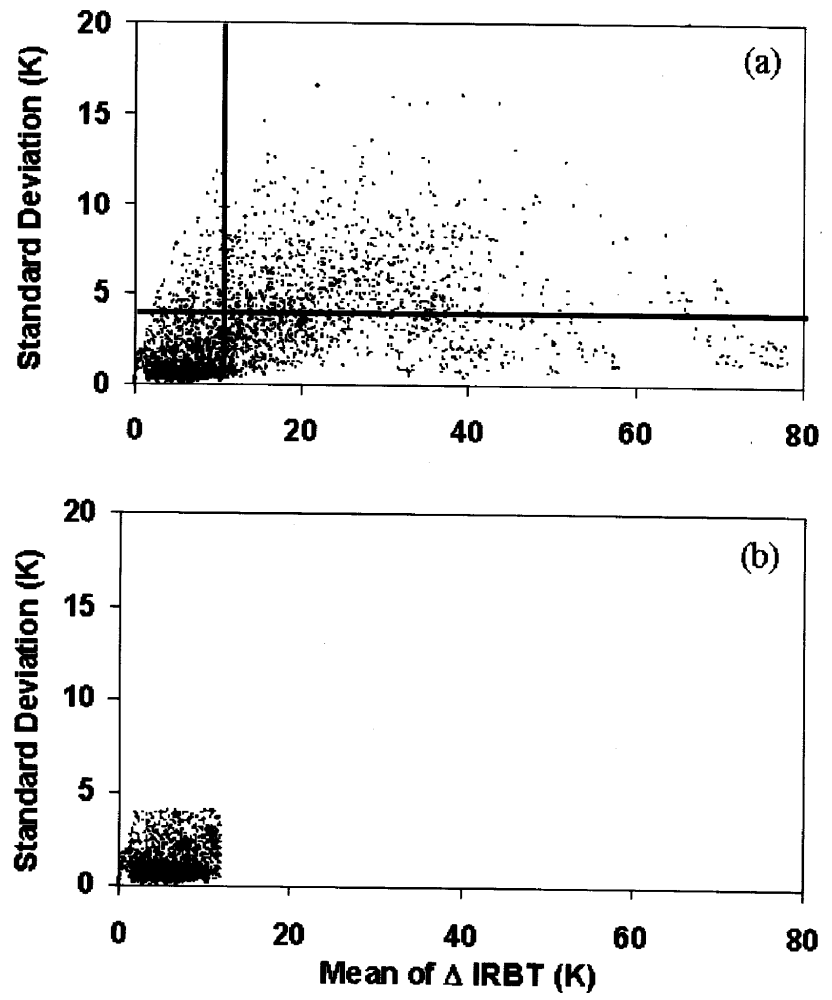

Fig. 3. Arch diagrams for a $3 \times 3$ pixel array of a $60 \times 60$ pixel box from a Difference Image (DI) and their classification according to the cloud algorithm. A typical arch with its clear foot delimited (top panel) and the foot classified as fully clear (bottom panel).

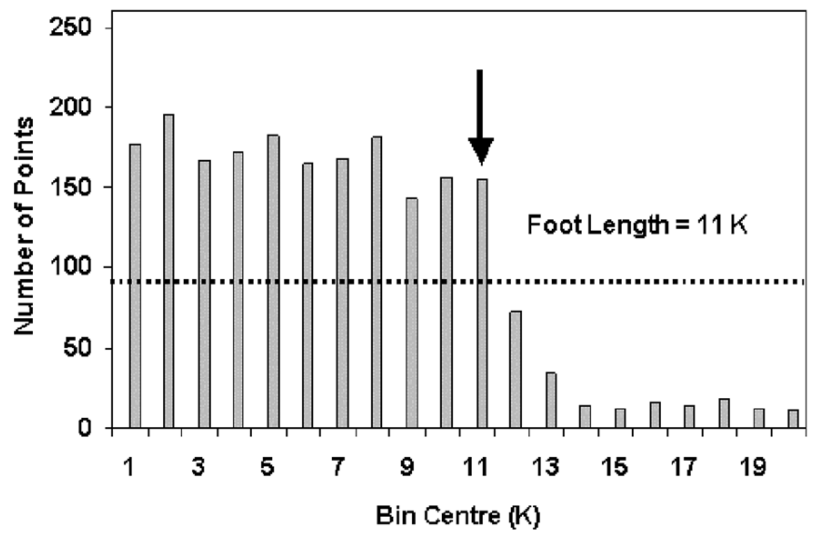

Fig. 4. The number of points per bin of $1 \mathrm{~K}$ in width. The point at which the number of points drastically decreases (to less than $50 \%$ of the average of the previous bins) was assigned as a clear foot.

where $R_{t}^{\uparrow}$ is the radiance leaving the TOA and $R_{b}^{\uparrow}$ is the radiance leaving the TOA without dust.

The IDDI images were created using radiometric counts (RC) from METEOSAT-5. Radiometric counts are first converted into radiance using the following relation:

Radiance $=$ CalibrationCoefficient $*\left(\mathrm{C}_{\mathrm{a}}-\mathrm{C}_{\mathrm{s}}\right)$,
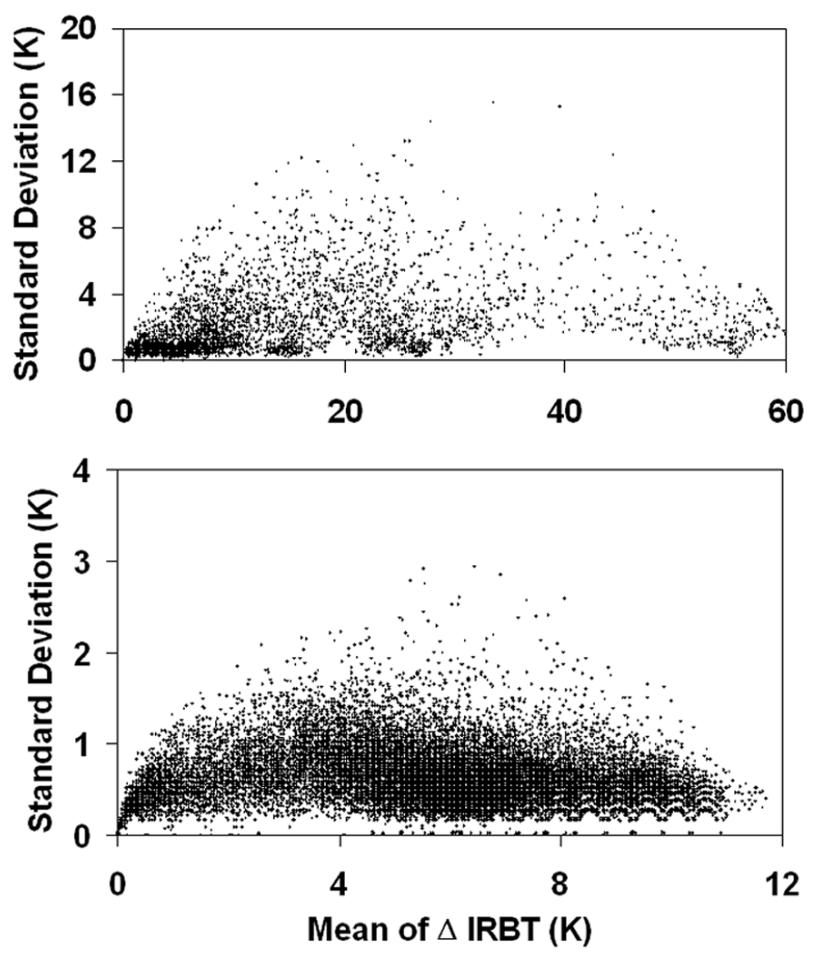

Fig. 5. Arch diagrams for a $3 \times 3$ pixel array of a $60 \times 60$ pixel box from a Difference Image (DI) and their classification according to the cloud algorithm. An example of an arch without a clear foot classified as fully cloudy (top panel) and an arch classified as fully clear (bottom panel).

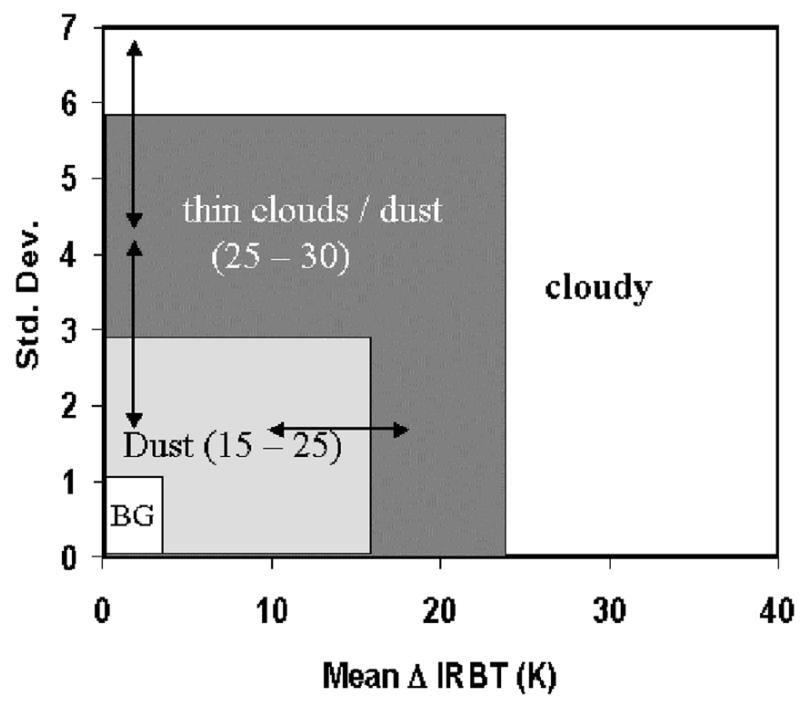

Fig. 6. A typical representation of the thresholds representing the background dust condition, normal dust conditions and cloudy conditions. The boundary between the clear and cloudy conditions is also shown. In this situation cloud screening is difficult.

where $\mathrm{C}_{\mathrm{a}}$ is actual satellite count, $\mathrm{C}_{\mathrm{s}}$ is the space count and Calibration Coefficient is provided by METEOSAT, along 


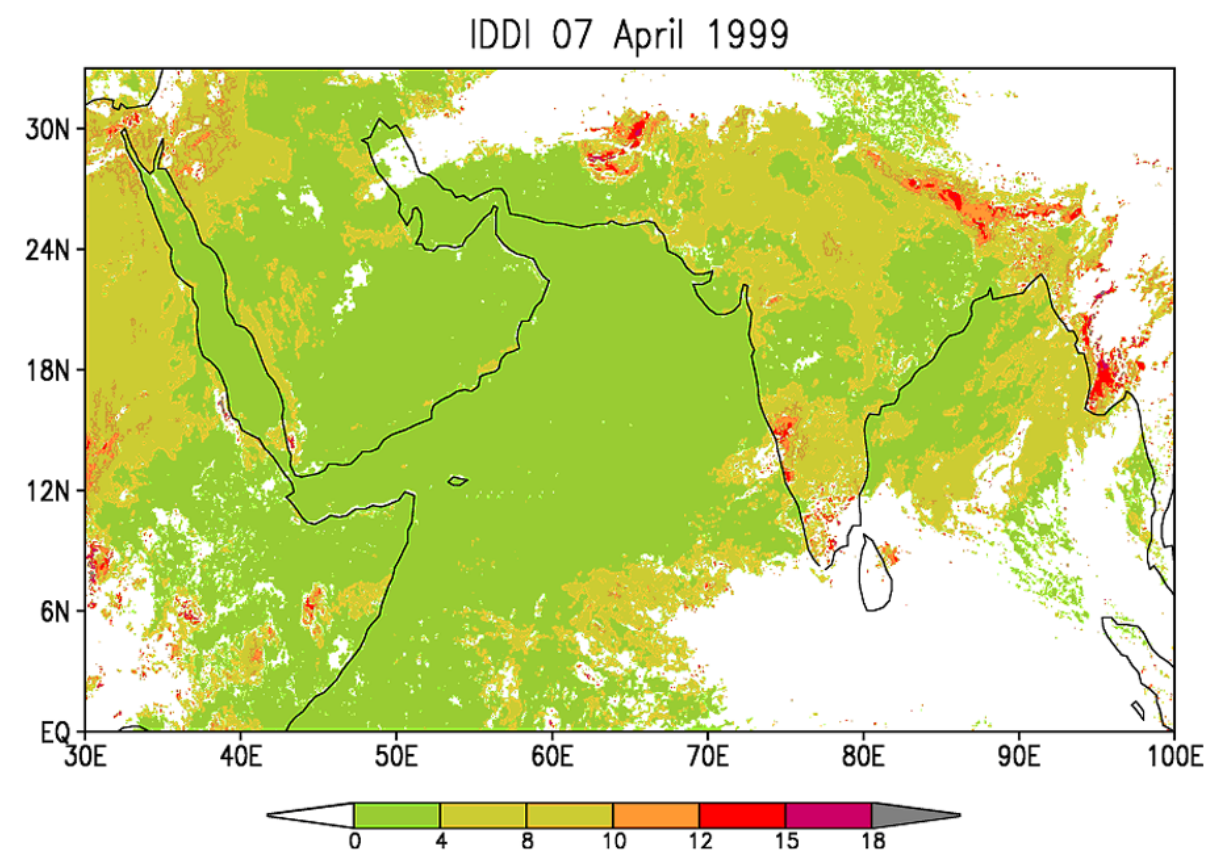

Fig. 7. The final IDDI image (in K) after cloud screening the difference image. This image represents the regional distribution of dust aerosols.

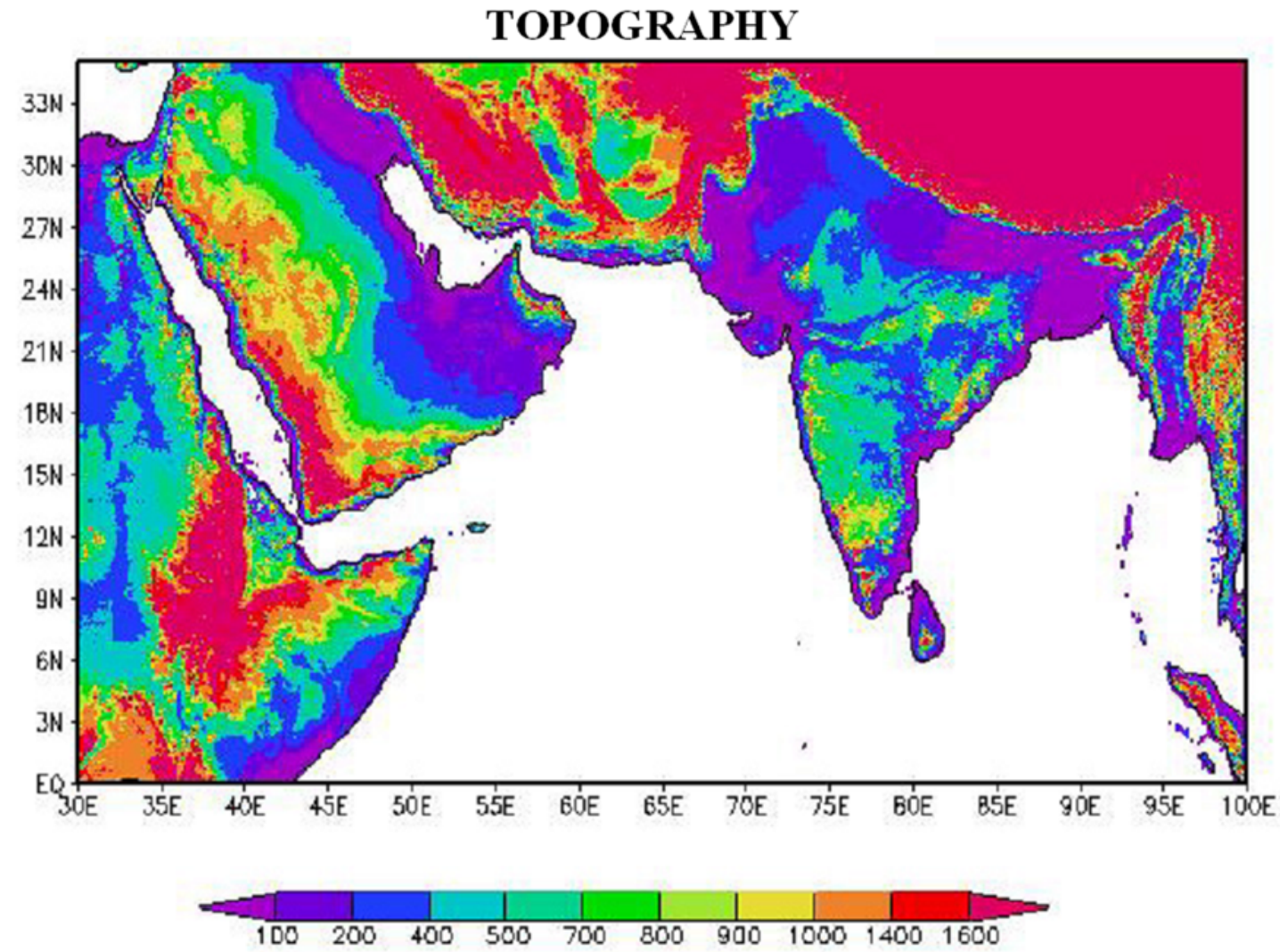

Fig. 8. Topography map of the METEOSAT-5 window region. 


\section{Vegetation Index (MODIS): January 2003}
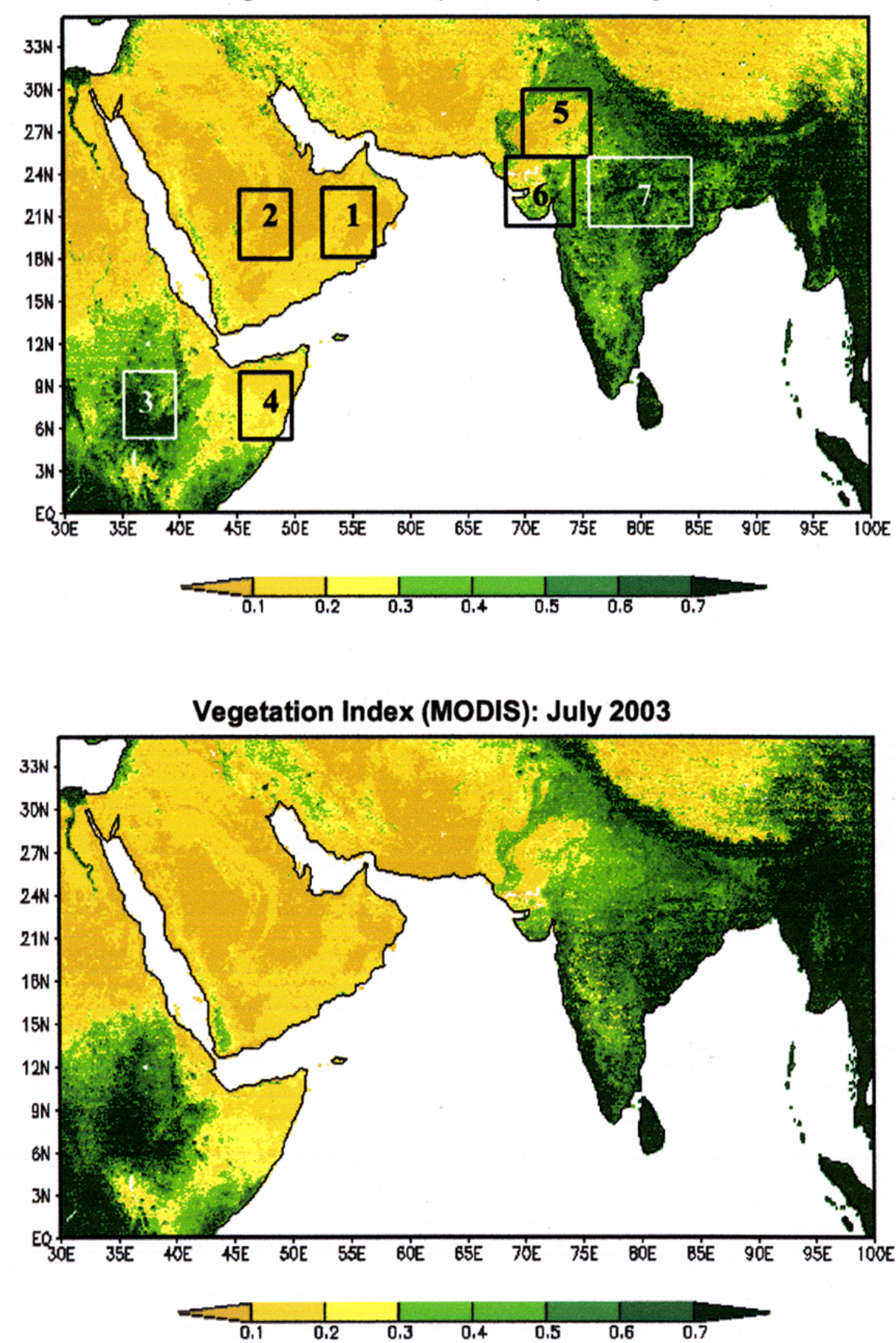

Fig. 9. Normalised Difference Vegetation Index (NDVI) maps of dry (January) and monsoon (July) months. The numbers inside the boxes represent the various regions which are used in the text to identify regions.

with the radiometric counts. Radiance data is converted into brightness temperature (IRBT) data, using an inverse Planck Function. This IRBT forms the original image (an example is shown in Fig. 2a). An "original image" contains all the radiative information about surface and atmosphere (Legrand et al., 2001).
The next step was to create a "reference image" representing clear-sky conditions for consecutive, non-overlapping periods, whose duration is short enough to eliminate the seasonal effects but long enough to ensure that the clear-sky or near clear-sky conditions exist for least one measurement, for each pixel (Legrand et al., 2001). The purpose of the 


\section{Surface Soil Moisture (fraction) 1999}
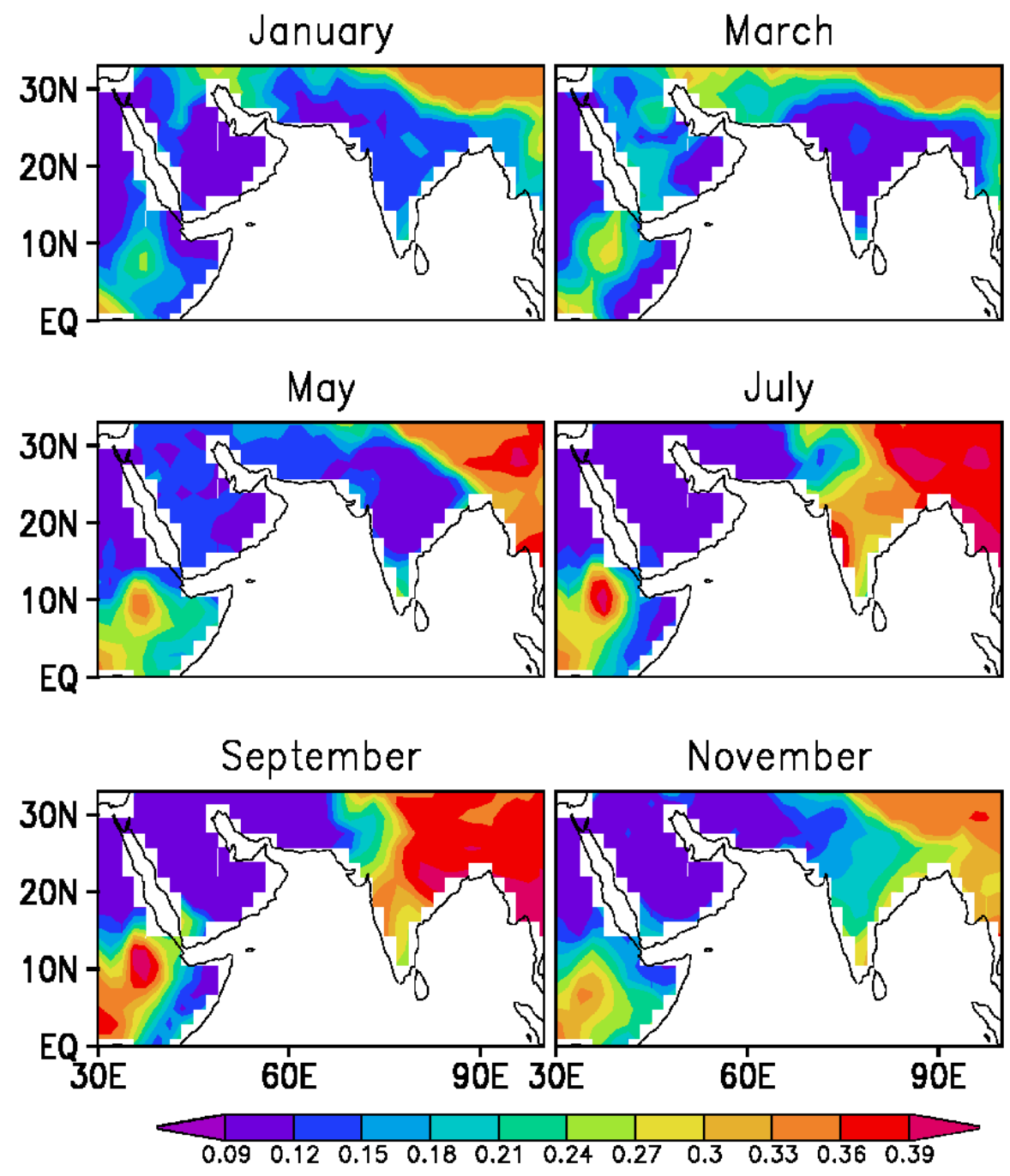

Fig. 10. The monthly average regional distribution of soil moisture during 1999 over India and adjacent continents for six representative months.

"reference image" is to separate the land effect from the "original image". A 15-day reference period is used here. For a given pixel, the maximum in the daily values of IRBT within a given reference period is assumed to represent the characteristics of the target pixel, as in cloud-free and dust free (background) conditions (Fig. 2b). Next, a "difference image", exhibiting the clouds and dust patterns separated from the permanent surface features, was obtained by subtracting the individual day "original image" (or IRBT) from the "reference image" for that period. The "difference image" (Fig. 2c) shows only the variable atmospheric radiative effects related to both clouds and dust (Legrand et al., 2001). Difference values represent the reduction in IRBT due to dust aerosols, provided that cloudy pixels are identified and screened.
Since the permanent surface patterns in the difference image are eliminated, clouds are observed over continental regions against a smooth, somewhat ocean-like, background (Legrand et al., 2001). This makes it easier to identify clouds in a "difference image" than in the "original image". Cloudy pixels were screened using the spatial coherence method (Coackley and Bretherton, 1982). First, cloudy pixels were identified in the "difference image" by dividing the whole image into regions of $60 \times 60$ pixel boxes. The local mean and standard deviation of the surrounding $3 \times 3$ pixel window was estimated within the pixel box and plotted, as shown in Fig. 3a. If the box considered is partly cloudy, then the plot forms an "arch" with areas of high coherence, with a low standard deviation, and areas with low coherence, with high standard deviations. If we set threshold values for the mean and standard deviation, which define the cloud-free area, we 
MODIS Water Vapor (cm)

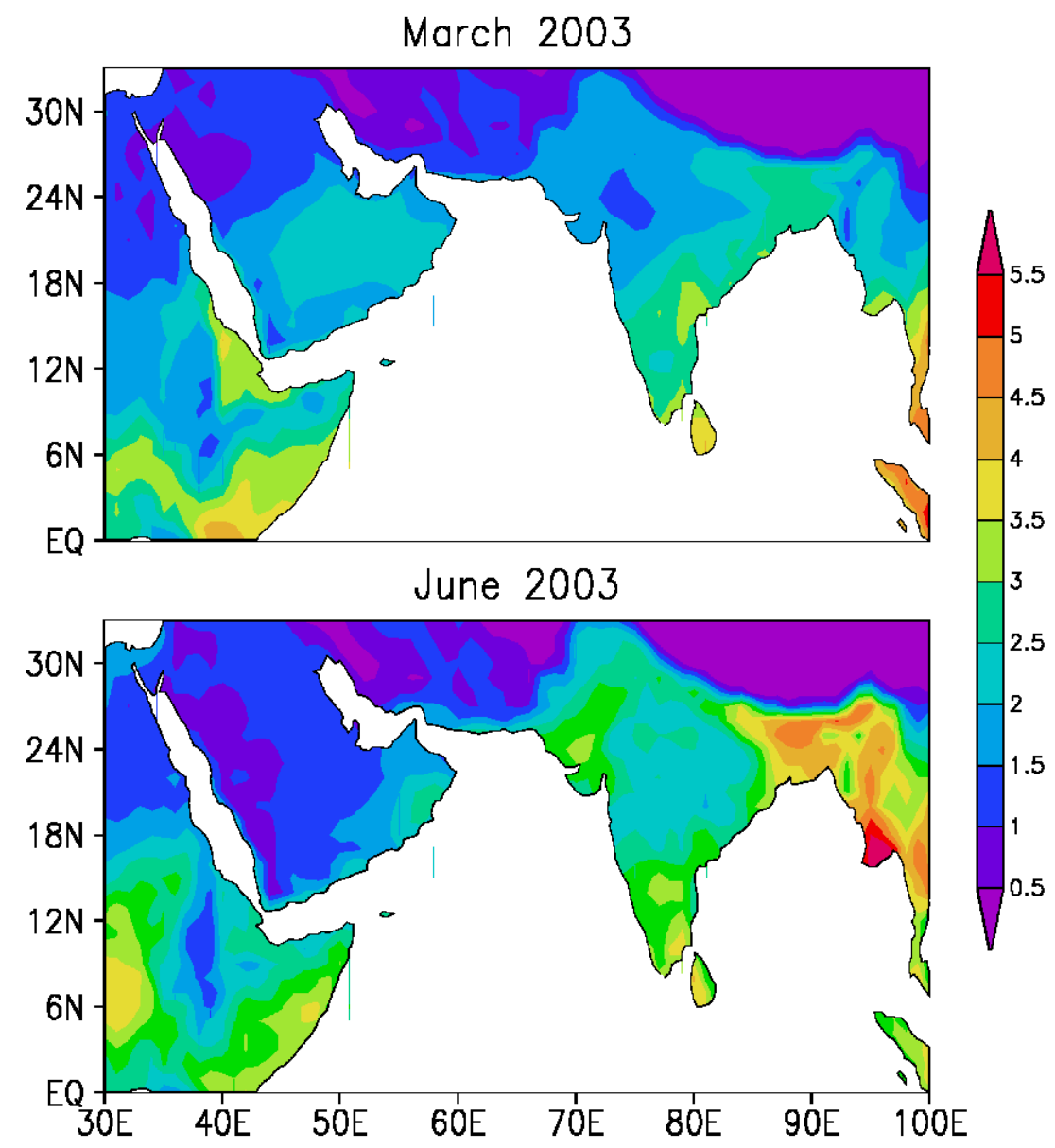

Fig. 11. Clear-sky column water vapour content derived from MODIS data using a near-infrared method.

can separate the clouds from the scene (Fig. 3b). In the "difference image", pixels, which lie outside the threshold of the mean and standard deviations, are identified as cloudy pixels and are masked. In order to find the thresholds, which define the clear-sky scene, we need to separate the clear foot of the arch in Fig. 3a. For this purpose, we have divided the $\mathrm{x}$-axis of Fig. 3a into 1-K bins and estimated the number of points lying within each bin. For this purpose, we have arbitrarily assigned a threshold standard deviation of $5 \mathrm{~K}$ (please note that this is not the final threshold), which is much larger than the standard deviation expected for dust but lower than that expected for cloudy scenes. The bin at which the number of points drastically decreases (to less than $50 \%$ of the average of previous bins) was assigned as the clear foot. In this example the clear foot was identified as $11 \mathrm{~K}$ (see Fig. 4).

The next step was to find the threshold for standard deviation, which defines clear-sky area. The threshold standard deviation is defined (in this study) as the standard deviation below which $90 \%$ of the points within the clear foot exist.
Typically the threshold standard deviation was in the range from 1 to $2 \mathrm{~K}$. In this way, depending on the amount and type of clouds, threshold values (clear foot and threshold standard deviation) are different for different scenes.

In the case of completely cloudy scenes, the plot of local mean versus standard deviation does not have an arch structure. An example is shown in Fig. 5 (top panel). Similarly, in the case of completely clear scenes, there will be usually only one foot with a very low standard deviation, as low as $2 \mathrm{~K}$ or even less (Fig. 5, bottom panel). These scenes can be identified as completely clear-sky scenes. A typical representation of the thresholds (mean and standard deviation), representing background dust condition, normal dust conditions and cloudy conditions, are shown in Fig. 6. Now the resulting image after cloud screening (an example is shown in Fig. 7) is an IDDI image, which represents the regional distribution of dust. Daily IDDI images were created after cloud screening. Thus, four steps of data processing are involved in order to create IDDI images. 


\section{NCEP Monthly Mean Surface Winds : 1999}
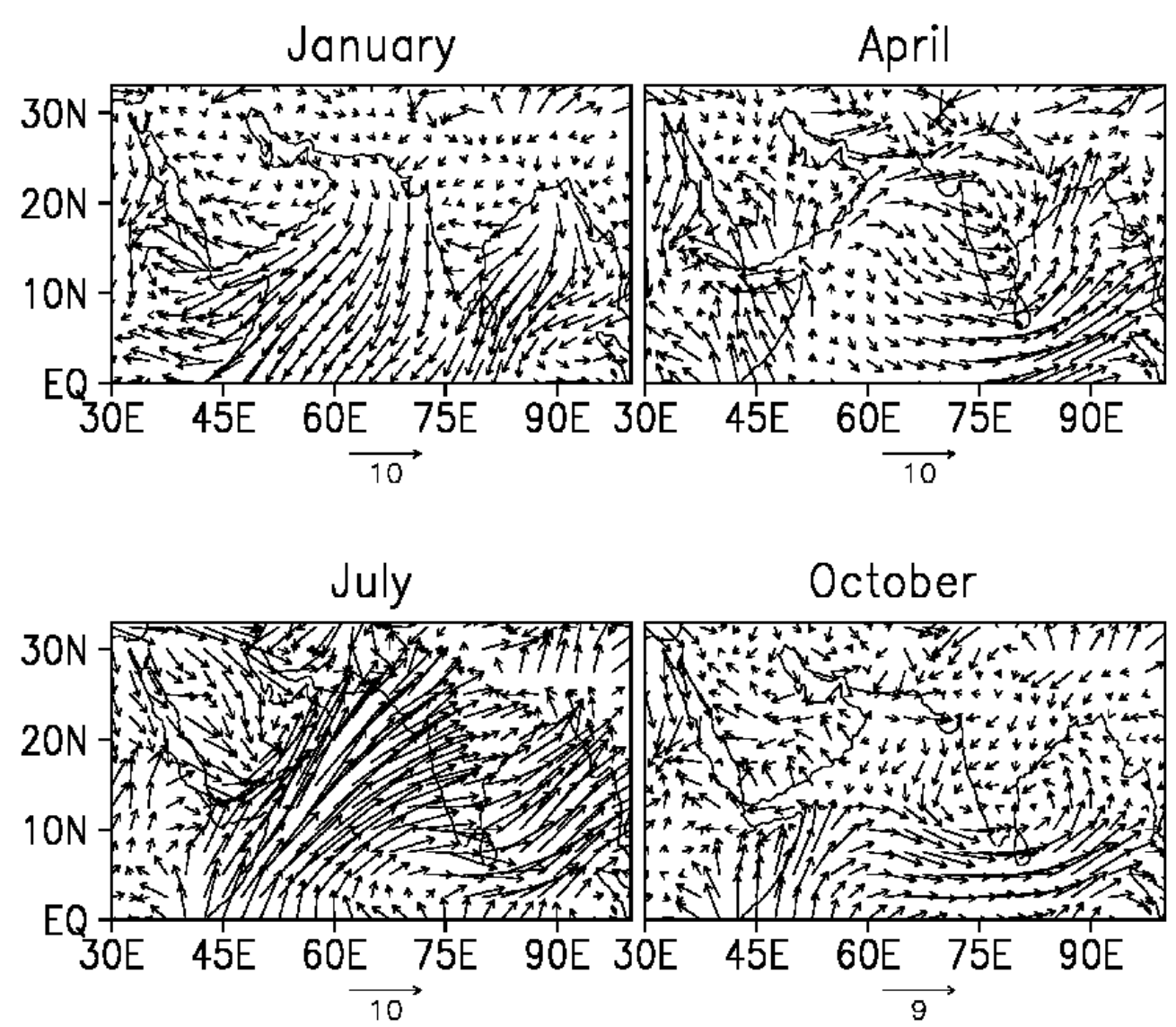

Fig. 12. The monthly regional distribution of surface winds during 1999 over India and adjacent continents for four representative months. The length of the arrows represent the magnitude of wind speed and its direction represents wind direction.

The METEOSAT IR radiance data were analysed for all days during 1999. These results were compared with a year with a large number of dust storms reported by meteorological departments based on visibility data (i.e. 2003). The seasonal variation and regional distribution of dust aerosols over arid and semiarid regions of India and adjacent continents are studied. There have been studies in the past carried out over Sahara using IDDI. Over the Indian region, however, studies on dust are sparse. In addition to METEOSAT IR radiance, vegetation index, water vapour content and fire pixel count (a measure of biomass burning location) from MODIS (on board TERRA satellite) were also used. The NCEP/NCAR reanalysed surface soil moisture and surface winds were also used to support the results.

\section{Results and discussion}

It is necessary to consider the temporal and spatial scales over which dust is most likely to interact with the processes which determine the regional climate, in order to identify the regions and seasons during which dust aerosols are present (Brooks and Legrand, 1999; Brooks, 2000; Legrand et al., 2001). It has been postulated that large dust loading over widespread areas in arid and semiarid zones might reduce surface heating sufficiently to affect the dynamics of the regional circulation pattern (Brooks and Legrand, 1999; Brooks, 2000). Dust events are likely to have an impact on the thermal structure of the atmosphere (Tegen and Fung, 1994). Prolonged impact of atmospheric dust on the largescale regional circulation would arise from generally elevated dust levels over periods longer than those associated with individual events (N'Tchayi et al., 1997; Brooks and Legrand, 1999). It is therefore important to examine variations in dust loading on a monthly or seasonal scale. 
Table 2. Comparison of Monthly Mean IDDI (K).

\begin{tabular}{|l|c|l|l|l|l|l|}
\hline \multirow{2}{*}{ Month } & \multicolumn{2}{|c|}{ Saudi Arabia-I } & \multicolumn{2}{c|}{ Saudi Arabia-II } & \multicolumn{2}{c|}{ Rajasthan } \\
\cline { 2 - 7 } & 1999 & 2003 & 1999 & 2003 & 1999 & 2003 \\
\hline Jan & $4.0 \pm 1.9$ & $4.4 \pm 2.3$ & $4.3 \pm 1.7$ & $6.0 \pm 2.1$ & $6.1 \pm 1.9$ & $5.3 \pm 2.2$ \\
\hline Feb & $4.6 \pm 1.9$ & $5.6 \pm 3.4$ & $5.5 \pm 1.6$ & $6.7 \pm 1.8$ & $6.2 \pm 2.5$ & $6.5 \pm 3.8$ \\
\hline Mar & $5.5 \pm 2.1$ & $6.7 \pm 3.6$ & $6.6 \pm 1.9$ & $8.2 \pm 2.7$ & $6.4 \pm 3.2$ & $5.7 \pm 2.5$ \\
\hline Apr & $4.9 \pm 1.9$ & $7.3 \pm 3.9$ & $5.5 \pm 2.0$ & $7.8 \pm 2.4$ & $4.1 \pm 1.6$ & $6.5 \pm 3.2$ \\
\hline May & $5.0 \pm 3.0$ & $6.3 \pm 2.8$ & $6.1 \pm 2.2$ & $6.6 \pm 2.5$ & $8.7 \pm 3.8$ & $7.4 \pm 3.5$ \\
\hline Jun & $4.5 \pm 1.6$ & $5.6 \pm 2.6$ & $4.3 \pm 1.7$ & $5.2 \pm 1.9$ & $7.3 \pm 3.4$ & $8.5 \pm 3.1$ \\
\hline Jul & $5.3 \pm 1.9$ & $6.9 \pm 2.6$ & $4.5 \pm 1.6$ & $5.8 \pm 1.8$ & $8.6 \pm 4.4$ & $9.3 \pm 3.5$ \\
\hline Aug & $4.1 \pm 0.9$ & $6.3 \pm 3.7$ & $3.9 \pm 1.3$ & $6.3 \pm 2.6$ & $6.4 \pm 3.9$ & $7.3 \pm 2.7$ \\
\hline Sep & $5.1 \pm 0.7$ & $5.3 \pm 1.5$ & $3.8 \pm 1.4$ & $5.6 \pm 1.6$ & $5.7 \pm 2.3$ & $7.0 \pm 2.8$ \\
\hline Oct & $5.0 \pm 1.0$ & $5.8 \pm 2.6$ & $3.5 \pm 1.1$ & $5.7 \pm 1.8$ & $4.4 \pm 2.5$ & $3.8 \pm 2.1$ \\
\hline Nov & $3.7 \pm 1.5$ & $4.3 \pm 1.9$ & $3.7 \pm 1.2$ & $4.5 \pm 1.6$ & $3.5 \pm 1.8$ & $4.2 \pm 2.3$ \\
\hline Dec & $2.5 \pm 0.6$ & $4.7 \pm 2.5$ & $2.7 \pm 0.8$ & $4.6 \pm 1.8$ & $3.8 \pm 1.9$ & $3.7 \pm 2.6$ \\
\hline $\begin{array}{l}\text { Annual } \\
\text { Average }\end{array}$ & $4.5 \pm 0.84$ & $5.8 \pm 1.0$ & $4.6 \pm 1.0$ & $6.1 \pm 1.1$ & $5.9 \pm 1.7$ & $6.3 \pm 1.8$ \\
\hline
\end{tabular}

Table 3. Comparison of Monthly Mean IDDI (K).

\begin{tabular}{|l|c|l|l|l|}
\hline \multirow{2}{*}{ Month } & \multicolumn{2}{|c|}{ NE Africa } & \multicolumn{2}{c|}{ Somalia } \\
\cline { 2 - 5 } & 1999 & 2003 & 1999 & 2003 \\
\hline Jan & $4.9 \pm 2.9$ & $6.1 \pm 2.8$ & $4.4 \pm 2.5$ & $5.9 \pm 2.6$ \\
\hline Feb & $4.2 \pm 1.7$ & $6.0 \pm 2.2$ & $5.2 \pm 1.8$ & $5.6 \pm 2.3$ \\
\hline Mar & $6.7 \pm 2.0$ & $7.2 \pm 2.1$ & $6.4 \pm 1.6$ & $6.9 \pm 2.0$ \\
\hline Apr & $7.0 \pm 2.6$ & $8.5 \pm 2.4$ & $6.8 \pm 2.2$ & $7.8 \pm 2.1$ \\
\hline May & $6.4 \pm 2.3$ & $6.8 \pm 2.1$ & $6.2 \pm 2.5$ & $7.2 \pm 1.9$ \\
\hline Jun & $6.1 \pm 2.3$ & $7.5 \pm 2.0$ & $6.4 \pm 2.6$ & $8.1 \pm 2.2$ \\
\hline Jul & $8.0 \pm 1.9$ & $7.6 \pm 1.7$ & $8.3 \pm 2.4$ & $9.0 \pm 2.7$ \\
\hline Aug & $6.6 \pm 1.9$ & $8.0 \pm 2.5$ & $7.1 \pm 2.1$ & $7.3 \pm 2.6$ \\
\hline Sep & $5.8 \pm 1.7$ & $6.5 \pm 1.4$ & $6.0 \pm 1.8$ & $6.7 \pm 2.1$ \\
\hline Oct & $7.3 \pm 2.6$ & $6.1 \pm 1.7$ & $6.3 \pm 2.1$ & $6.4 \pm 1.9$ \\
\hline Nov & $4.8 \pm 1.6$ & $6.3 \pm 2.6$ & $5.8 \pm 1.4$ & $6.5 \pm 2.5$ \\
\hline Dec & $3.1 \pm 1.1$ & $6.4 \pm 3.3$ & $3.4 \pm 1.3$ & $6.8 \pm 2.4$ \\
\hline $\begin{array}{l}\text { Annual } \\
\text { Average }\end{array}$ & $5.9 \pm 1.4$ & $6.9 \pm 0.8$ & $6.0 \pm 1.3$ & $7.0 \pm 1.0$ \\
\hline
\end{tabular}

4.1 Surface soil condition, surface wind and atmospheric water vapour

The topography map of the study region is shown in Fig. 8, which provides information about altitude of various locations within METEOSAT-5 window. Dust production depends on soil moisture, surface wind speed and surface soil conditions (e.g. existence of vegetation). For a given wind speed, the dust production rate at the surface depends on soil moisture (in the absence of vegetation) (Gillettte, 1979; Jaenicke, 1980, 1993; Prospero et al., 1983, 2002). In semiarid regions, however, vegetation cover may have a greater influence than soil moisture, since permanent seasonal vegetation persists, which inhibits dust production even when the soil moisture becomes too low. Therefore, we show in Fig. 9, a normalised difference vegetation index (NDVI) derived from MODIS (on board TERRA satellite) data for both dry (January) and monsoon (July) months. The areas represented in green (typically NDVI $>0.3$ ) are vegetated areas. We did not find any significant seasonal variation in vegetation cover over the study area except in central India and the northeast African region. Over central India during January, more than $90 \%$ of the pixels had NDVI $>0.3$ while during June this was about $75 \%$. The MODIS has provided NDVI data at a $1-\mathrm{km}$ resolution. But year-round MODIS data is available from 2000 only. This is the reason we presented vegetation index maps for 2003 instead of 1999. The boxes shown in Fig. 9 (top panel) represent boundaries of regions considered for studying the temporal characteristics of dust (discussed later in Sect. 4.3) and are numbered from (1) to (7). The monthly regional distribution of soil moisture during 1999 over India and adjacent continents is shown in Fig. 10 (from NCEP/NCAR). Soil moisture is a measure of surface wetness. The Indian deserts are dry from December to May. After the onset of monsoon rainfall, soil moisture over these regions becomes higher (in June to November period). This seasonal pattern of soil moisture is more or less similar over central Africa, as well. The Arabian Desert, on the other hand, is dry during most of the year.

The regional distribution of clear-sky column water content (from MODIS) is derived using a near-infrared method during both the dry and monsoon months (see Fig. 11). 
Table 4. Comparison of Daily Maximum IDDI (K).

\begin{tabular}{|l|c|c|c|c|c|c|c|c|}
\hline \multirow{2}{*}{ Month } & \multicolumn{2}{|l}{ Saudi Arabia-I } & \multicolumn{2}{l}{ Saudi Arabia-II } & \multicolumn{2}{l}{ Rajasthan } & \multicolumn{2}{l|}{ C. India } \\
\cline { 2 - 10 } & 1999 & 2003 & 1999 & 2003 & 1999 & 2003 & 1999 & 2003 \\
\hline Jan & 9.6 & 10.0 & 10.2 & 9.7 & 11.0 & 8.3 & 6.4 & 7.7 \\
\hline Feb & 8.4 & 12.9 & 8.5 & 12.6 & 11.8 & 15.2 & 7.8 & 9.4 \\
\hline Mar & 12.4 & 16.3 & 12.8 & 15.8 & 14.0 & 16.6 & 6.6 & 10.3 \\
\hline Apr & 10.8 & 18.0 & 11.3 & 17.8 & 12.5 & 12.4 & 7.1 & 8.6 \\
\hline May & 16.4 & 16.5 & 16.8 & 17.2 & 18.0 & 14.1 & 11.8 & 10.6 \\
\hline Jun & 8.5 & 12.1 & 10.3 & 13.2 & 12.5 & 13.6 & 11.7 & 12.0 \\
\hline Jul & 17.6 & 14.0 & 17.8 & 16.2 & 16.2 & 14.0 & 13.7 & 12.1 \\
\hline Aug & 8.2 & 15.7 & 9.2 & 15.8 & 13.8 & 13.0 & 10.7 & 11.3 \\
\hline Sep & 8.0 & 14.2 & 8.6 & 13.6 & 9.9 & 11.8 & 7.5 & 9.6 \\
\hline Oct & 11.2 & 9.6 & 11.7 & 11.3 & 13.5 & 8.6 & 10.7 & 7.8 \\
\hline Nov & 10.5 & 11.7 & 11.3 & 12.3 & 7.0 & 11.8 & 7.9 & 4.8 \\
\hline Dec & 5.1 & 10.4 & 5.3 & 10.8 & 7.1 & 11.0 & 5.7 & 9.0 \\
\hline $\begin{array}{l}\text { Annual } \\
\text { Average }\end{array}$ & 10.6 & 13.5 & 11.2 & 13.9 & 12.3 & 12.5 & 9.0 & 9.4 \\
\hline
\end{tabular}

Legrand et al. (2001) has made detailed sensitivity analysis on the role of atmospheric water vapor in contaminating IDDI. They reported that when the water vapor amount is in the range between 0.5 and $2.5 \mathrm{~g} \mathrm{~cm}^{-2}$, maximum variation in simulated METEOSAT infrared response (IDDI) is not greater than $2 \mathrm{~K}$. When the water vapor amount exceeds $3 \mathrm{~g} \mathrm{~cm}^{-2}$, the effect of the water vapor becomes important. Over arid and semiarid locations water vapor amount is usually less than $2.5 \mathrm{~g} \mathrm{~cm}^{-2}$ during most of the time in a year. Over locations experiencing a water vapor amount exceeding $3 \mathrm{~g} \mathrm{~cm}^{-2}$, water vapor absorption contributes to IDDI. We have made estimates of the effect of water vapor on IDDI based on Fig. 11, which shows that over most of the study region the effect of water vapor on IDDI is as high as $3 \mathrm{~K}$ (especially within the boxes shown in Fig. 9).

Investigations in the past have reported that the threshold wind speed required for dust production starts at $4 \mathrm{~m} \mathrm{~s}^{-1}$ (Helgren and Prospero, 1987; Nickling and Gillies, 1989). However, studies carried out later have shown that a wind speed above $0.5 \mathrm{~m} \mathrm{~s}^{-1}$ is capable of transporting the mineral dust particles in the atmosphere as large as $2 \mu \mathrm{m}$ in size (McTainsh, 1980; d'Almeida et al., 1991). When soil moisture is low (in the absence of vegetation) the magnitude of the surface wind is mainly responsible for the production of dust from the surface. Therefore, we show a regional distribution of surface $(10 \mathrm{~m}$ ) winds (obtained from NCEP/NCAR reanalysis) during 1999 over India and adjacent continents in Fig. 12. The length of the arrows represents the magnitude of the wind speed, and its direction indicates the wind direction. Surface winds have an important role not only on dust production but also in transporting dust from one region to another. Surface winds are weak ( 3 to $5 \mathrm{~m} \mathrm{~s}^{-1}$ ) during November to March throughout India and the adjacent regions. This is shown in Fig. 12 for January. The wind speed starts picking up from April and reaches a maximum (10 to $\left.12 \mathrm{~m} \mathrm{~s}^{-1}\right)$ during June/July. The net dust production at any location depends on the combined effect of wind and soil moisture. If the wind speed and soil moisture are both high, the dust production rate will be low. For example, over northwest India, when the wind speed peaks during June, July and August, soil moisture is also high due to monsoon rains. Thus, regions, such as Arabia, experiencing high wind speed and low soil moisture conditions (and nearly negligible vegetation) (Figs. 9 to 12), are expected to be the dominant dust sources.

\subsection{Seasonal variations in dust loading as inferred from IDDI}

Dust which is transported large distances may have an impact on climate far from its source (Li et al., 1996; Alpert et al., 1998; Schollaert and Merrill, 1998; Li et al., 2004). Different regions act as dust sources during different times of the year and hence the dust source function is different for different regions and for different seasons. Over source regions and neighboring land areas dominant aerosols are mineral dust particles. Outside these regions, other aerosols, such as biomass burning aerosols or sulphates, are also important. Airborne dust is likely to have the greatest impact on the radiative and optical properties of the atmosphere near its source where effective particle size and particle number density is the highest.

The noon-time IDDI images were constructed in order to examine dust variability over arid and semiarid regions of India, as well as Africa and Arabia. Here, only representative images of IDDI for the year 1999 are presented. However, discussions are based on IDDI maps for all days. More details are provided in Tables 2 to 5 . White areas are cloudy 

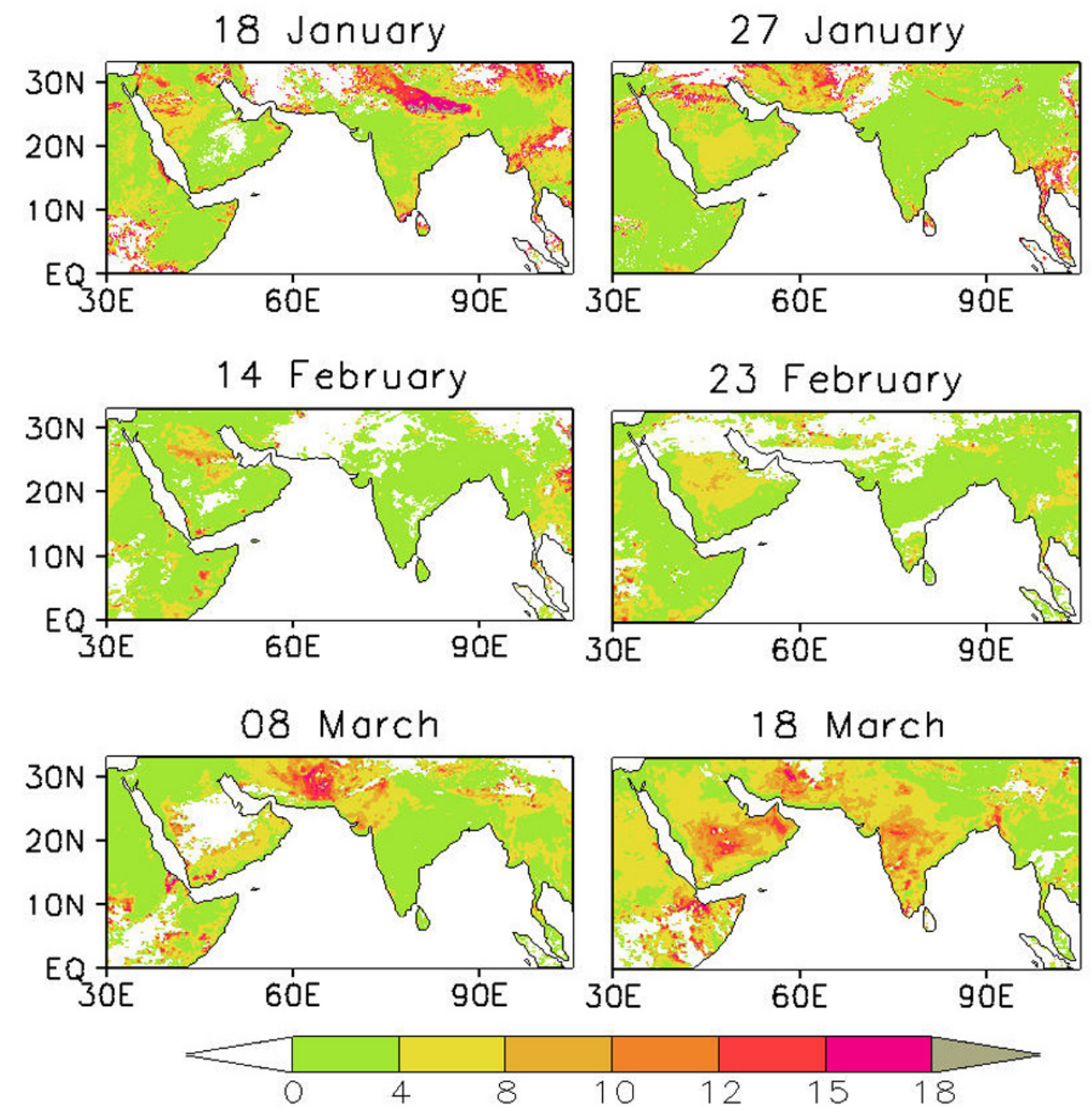

Fig. 13. Typical examples of regional distribution of IDDI (K) during January, February and March.

areas, which are screened by a cloud screening algorithm. Regions with IDDI larger than $6 \mathrm{~K}$ are easily distinguishable as regions with large dust loads (dusty areas). The IDDI values larger than $6 \mathrm{~K}$ correspond to dusty conditions, characterised by visibilities near the ground of less than $10 \mathrm{~km}$ and are approximately equivalent to an Aerosol Optical Depth (AOD) of 0.3-0.5 (Legrand et al., 1994). This can contribute to a radiative forcing of several $\mathrm{W} \mathrm{m}^{-2}$ on a local or regional scale, which is of the same order as the globally averaged enhanced greenhouse gas forcing (Lacis and Mischenko, 1995).

\subsubsection{January, February and March}

Noon-time data of the Meteosat-5 IR channel for all days of 1999 were analysed and low IDDI was observed over the Indian landmass during January (Figs. 13a, b). Over arid and semiarid regions of Northwest India, IDDI values were in the range of $2 \mathrm{~K}$ to $8 \mathrm{~K}$ (monthly average), which ares commonly observed values over desert regions. Studies of dust over the Sahara have demonstrated that a brightness temperature depression (i.e. IDDI) of $10 \mathrm{~K}$ is commonly observed throughout the year (Legrand et al., 2001). During January, soil moisture was very low over the deserts (Fig. 10) over Northwest India (Rajasthan). However, surface winds were also low $\left(\sim 3 \mathrm{~m} \mathrm{~s}^{-1}\right)$ during January (Fig. 12), which could be the reason for low IDDI. In parts of South India high IDDI values were occasionally observed (Fig. 13, for example). One interesting feature was observed over the northern part of India, where IDDI values were in the range of $12 \mathrm{~K}$ to $18 \mathrm{~K}$ and persisted for more than 10 days (i.e. from 7 to 21 January 1999) (Fig. 13a). These high values usually correspond to dust storm events and interestingly there were no dust storms reported during January in that region. Even though IDDI is less sensitive to biomass burning aerosols, in the aftermath of the biomass burning episode, black carbon aerosols might stick to large dust aerosols (resulting in large and highly absorbing dust aerosols) (Chandra et al., 2004; Seinfeld et al., 2004; Deepshikha et al., 2005), hence leading to higher IDDI values. Sensitivity studies discussed in previous sections have shown that IDDI is not sensitive to black carbon aerosols when it exists independently. But if black carbon is the result from biomass burning accumulation over 


\section{Terra Fire Pixel Count : 2003}
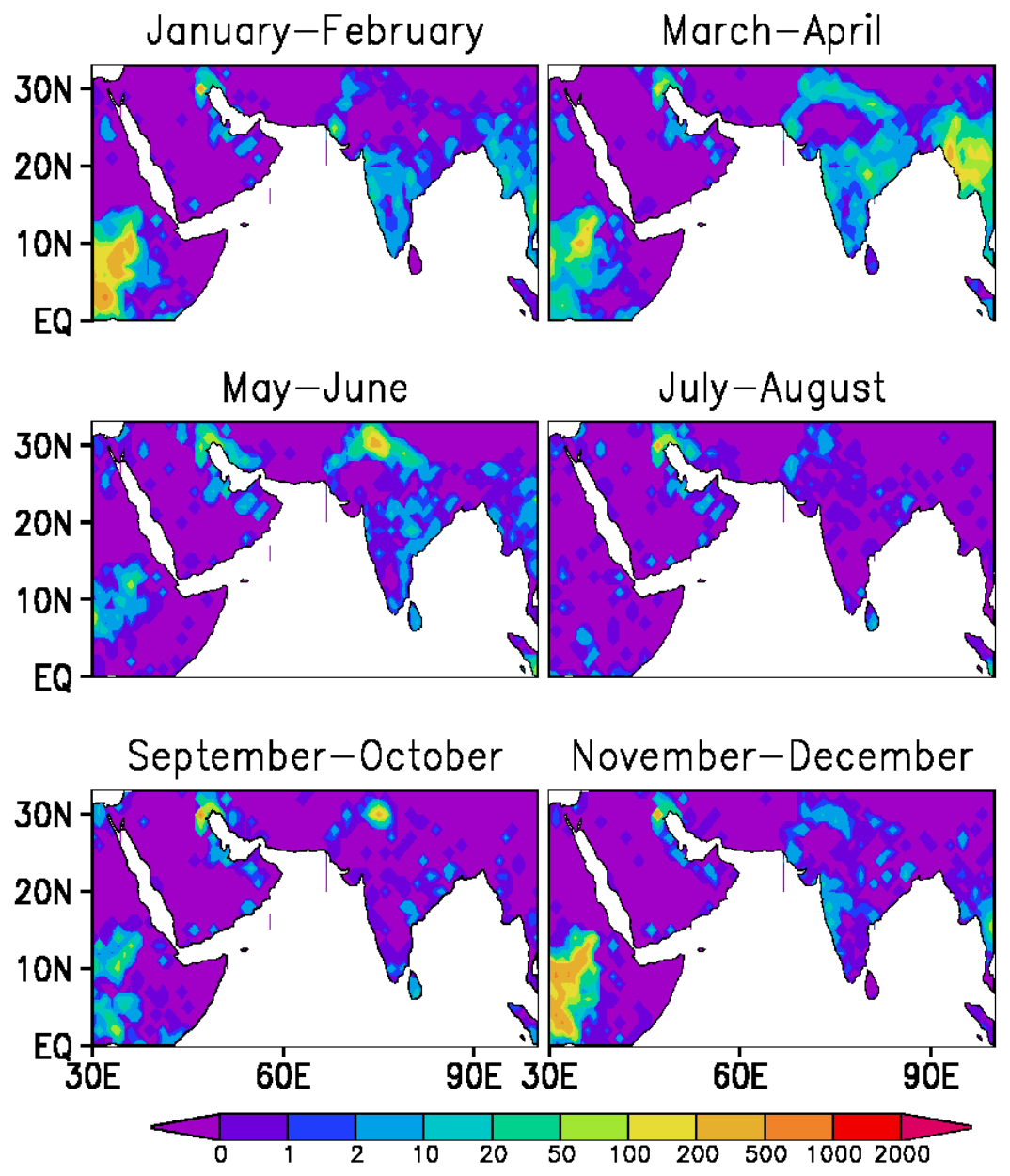

Fig. 14. Maps of fire pixel counts (from TERRA satellite data) which provide information on the period and regions of biomass burning.

dust, then it will have an impact on IDDI. To examine the period and regions of biomass burning, we show monthly maps of fire pixel counts (a measure of biomass burning) from TERRA satellite data in Fig. 14. Fire pixel counts are estimated from infrared satellite radiance and represent the number of occurrences of high infrared emission from the surface (biomass burning episodes). These maps show intense biomass burning activity over Southern India and IndoGangetic plains (Northern India) during the winter months (December to March). Therefore, these high values of IDDI (over Indo-Gangetic plains and South India) (see Fig. 13a) could probably be due to dust mixed with black carbon particles (from biomass burning). The influence of fog is ruled out, as we have examined the Relative Humidity (RH) data from meteorological observatories, which shows that RH decreases from $\sim 90 \%$ in the morning hours to less than $50 \%$ by around 11 a.m. (see also, Tripathi et al., 2005). Thus, noontime IDDI maps (which are reported in this paper) are not influenced by fog. The Indo-Gangetic plain is well known for a high load of black carbon and sulphate aerosols during the pre-monsoon season (Girolamo et al., 2005; Tripathi et al., 2005). These pollution aerosols also have an impact on the IDDI by decreasing the solar radiation at the surface. Sensitivity studies show that the effect of reduction of the solar radiation in IDDI is less than $10 \%$.

During February IDDI over the Arabian Desert has increased but over the Indian region it was still low. In Fig. 13c (14 February) a region with high IDDI values $(8-12 \mathrm{~K})$ can be seen over the Arabian region $\left(21^{\circ} \mathrm{N}-29^{\circ} \mathrm{N}\right.$ and $40^{\circ} \mathrm{E}-$ $50^{\circ} \mathrm{E}$ ), whereas the Indian region low values of IDDI were observed. Figure 13d (23 February) shows larger IDDI $(\sim 8 \mathrm{~K})$ over Saudi Arabia compared to the Indian region with a large area covered by dust. However, February was a month with low IDDI over the Indian arid and semiarid regions (Figs. 13c, d). From March onwards dust loading increased over arid and semiarid regions of India, as well as adjacent regions (Figs. 13e, f). The soil moisture was low (00.12 ) all over Northern India (Fig. 10). The surface wind pattern (NCEP/NCAR reanalysis data) in March /April (Fig. 12) shows that wind speeds in March/April are higher compared 


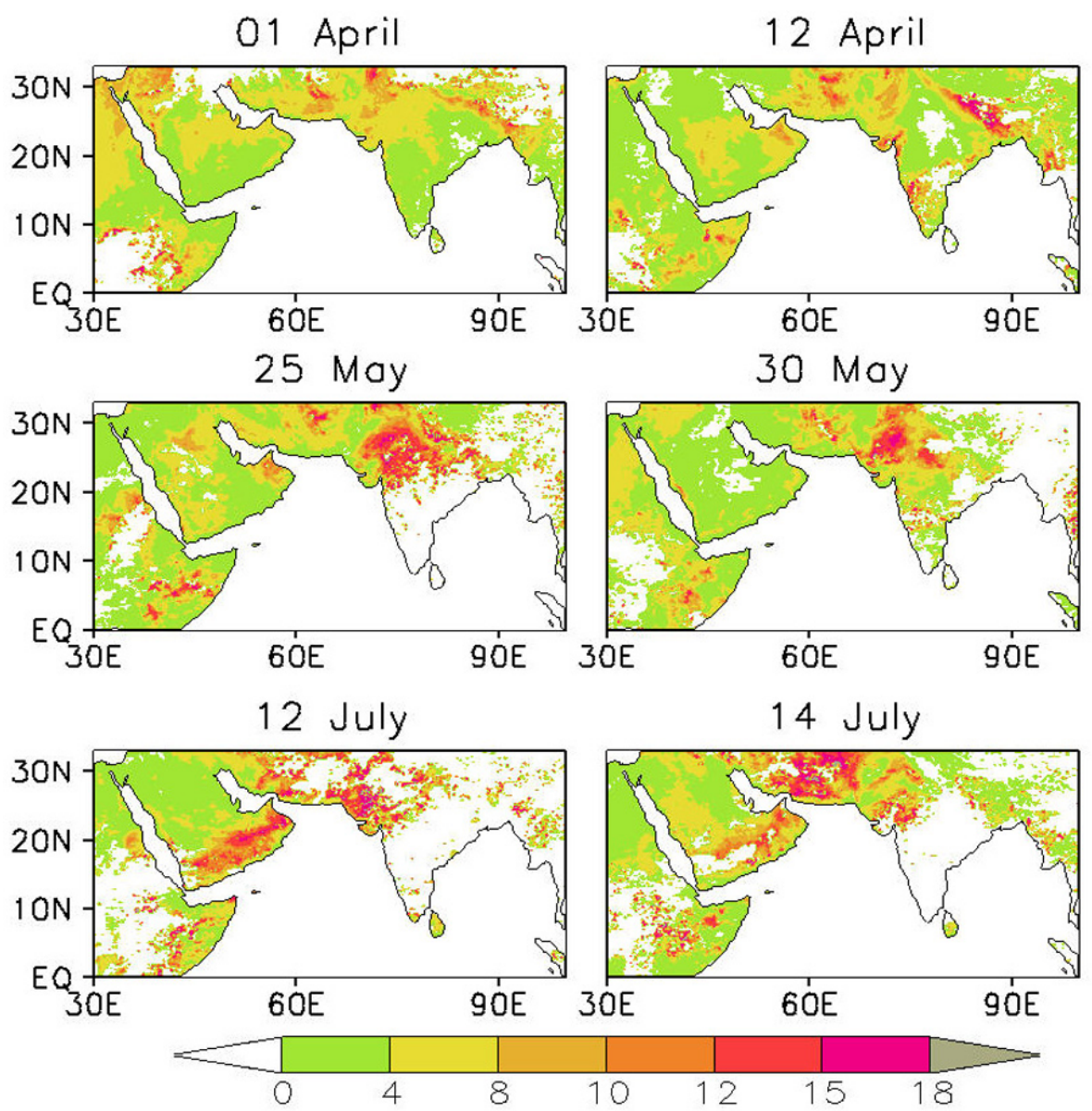

Fig. 15. Typical examples of regional distribution of IDDI (K) during April, May and July.

to January and February. The lower soil moisture and higher surface winds might have resulted in enhanced atmospheric dust loading over the source regions, as well as regions away from the source. Figures 13e, f show IDDI values as large as $15 \mathrm{~K}$ over most of India and Arabia. On 8 March over the Arabian Desert, no dust retrieval was possible because of clouds. On the same day, over the Indian desert and neighboring regions in Pakistan, Afghanistan and Iran, a mild dust storm was observed (Fig. 13e). Around the middle of March a high dust load was observed over the Arabian Desert and all over the northern part of India. In the southern part of India, around $18^{\circ} \mathrm{N}$, high IDDI was observed which could be due to dust aerosols transported or as a consequence of biomass burning aerosols sticking to local dust. Over Northwest India IDDI was, in general, high (in the range of $8 \mathrm{~K}-12 \mathrm{~K}$ ) during March (Figs. 13e, f).

\subsubsection{April, May and June}

During April, May and June large IDDI values were observed over arid and semiarid regions of India (Figs. 15a-d and Fig. 16). During April, May and June the northwest part of India is the driest and hottest (Fig. 10). Low soil moisture simultaneous with high wind speed caused the uplift of surface dust to the atmosphere and hence led to high IDDI over Northwest India (Figs. 10 and 12). In addition, the circulation pattern during this period favors transport of mineral dust aerosols from Northwest India towards Central India. Figures 15a, b show IDDI maps for two representative days of April 1999.

In May, winds were high, of the order of $\sim 10 \mathrm{~m} \mathrm{~s}^{-1}$. High winds could be one of the factors, which leads to high IDDI (Figs. 15c, d). The IDDI was the highest over Northwest India during April, May and June (Figs. 15c, d and Fig. 16). An analysis of daily IDDI values during this period indicates that there were several dust episodes lasting from a few hours to a few days. During May and June several dust storms were observed. Figures 15c, d show high IDDI on 25 and 30 May, which represents a dust storm covering the northwest part of India and a part of Pakistan and Afghanistan. This dust episode persisted from 19 May and prevailed until 31 May.

During May and June, IDDI values as high as $18 \mathrm{~K}$ were observed often over desert regions and even more than $18 \mathrm{~K}$ occasionally (Figs. 15c, d and Fig. 16). A typical example of a dust storm observed during June 1999 is shown in Fig. 16. The daily average wind pattern corresponding to the days of the dust storm is shown in Fig. 17. Note from Figs. 9 to 12 


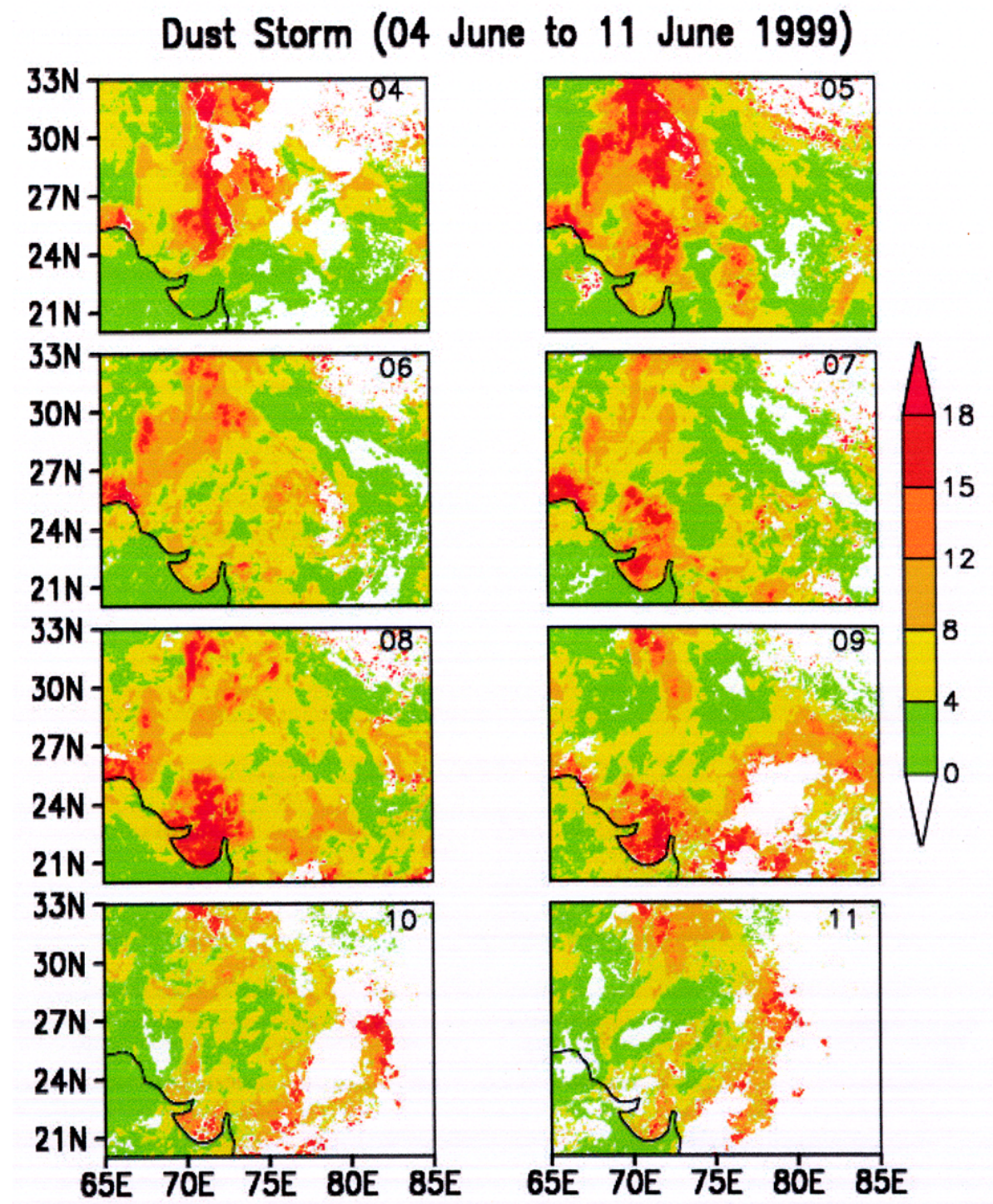

Fig. 16. A typical example of a dust storm observed during June 1999. Here IDDI is in K.

that Afghanistan (region above Rajasthan, which is Region-5 in Fig. 9) and the adjacent regions are dry during June/July and winds are quite high, of the order of $10 \mathrm{~m} \mathrm{~s}^{-1}$. The storm started on 4 June, reached its maximum on 5 June and thereafter faded in intensity, gradually to reach background levels by 11 June. Meanwhile, another high dust event occurred over the Gujarat region (northwest India; Region-6 in Fig. 9) on 7 June and reached its maximum on 8 June and reduced to background values in the next two days. Figure 17 shows that variations in wind speed play an important role in these two dust episodes. The daily variations of IDDI corresponding to these two dust storms are shown in Fig. 18. In both cases dust levels decreased to normal values in two to three days.

\subsubsection{July to December}

After the onset of southwest monsoon, dust detection was difficult due to cloudy conditions. In case clouds are covering an area where dust load is high, it is very difficult to distinguish between the dust and cloud patches. Thus, only a few days of IDDI data was available over the Indian region during monsoon season. Over the Arabian and African regions, however, data were available. During and immediately after the monsoon rains, soil moisture increased and wind speed became low (Figs. 10 and 12). Thus, during August and September IDDI over the Indian arid and semiarid regions were moderate (Fig. 19). However, from Figs. 15e, f and 19, it can be seen that IDDI was high over the Arabian Desert until November. From October onwards soil moisture starts reducing and gradually dry conditions are back over 
Table 5. Comparison of Daily Maximum IDDI (K).

\begin{tabular}{|l|c|c|c|c|c|c|}
\hline \multirow{2}{*}{ Month } & \multicolumn{2}{l|}{ NE Africa } & \multicolumn{2}{l|}{ Somalia } & \multicolumn{2}{l|}{ Gujarat } \\
\cline { 2 - 7 } & 1999 & 2003 & 1999 & 2003 & 1999 & 2003 \\
\hline Jan & 10.8 & 13.5 & 11.4 & 14.1 & 5.8 & 5.9 \\
\hline Feb & 5.9 & 8.4 & 7.1 & 9.6 & 5.2 & 10.0 \\
\hline Mar & 10.3 & 11.2 & 12.3 & 12.3 & 7.7 & 12.3 \\
\hline Apr & 10.2 & 12.9 & 10.4 & 13.1 & 6.7 & 11.4 \\
\hline May & 9.9 & 12.2 & 10.3 & 12.1 & 15.8 & 9.7 \\
\hline Jun & 12.7 & 12.5 & 13.2 & 12.4 & 15.6 & 11.0 \\
\hline Jul & 11.4 & 9.8 & 12.1 & 10.2 & 13.2 & 13.4 \\
\hline Aug & 8.5 & 13.0 & 9.5 & 12.8 & 9.8 & 14.2 \\
\hline Sep & 9.6 & 9.2 & 10.6 & 9.5 & 16.0 & 12.1 \\
\hline Oct & 14.0 & 10.9 & 14.4 & 10.5 & 6.0 & 6.1 \\
\hline Nov & 8.4 & 12.8 & 9.4 & 12.9 & 10.6 & 5.3 \\
\hline Dec & 5.8 & 11.4 & 6.3 & 11.8 & 6.2 & 8.0 \\
\hline $\begin{array}{l}\text { Annual } \\
\text { Average }\end{array}$ & 9.8 & 11.5 & 10.6 & 11.8 & 9.9 & 10.0 \\
\hline
\end{tabular}

\section{Winds (925 mb) (04 June to 11 June 1999)}

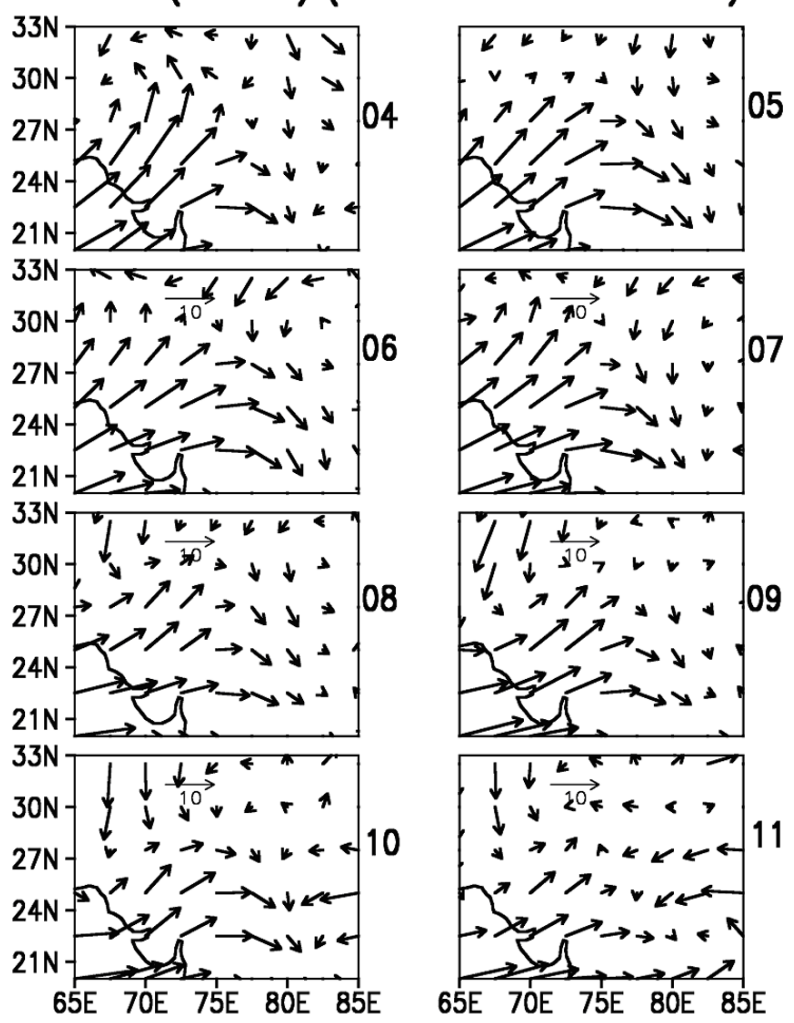

Fig. 17. Daily average wind pattern corresponding to days of dust storm shown in Fig. 13.

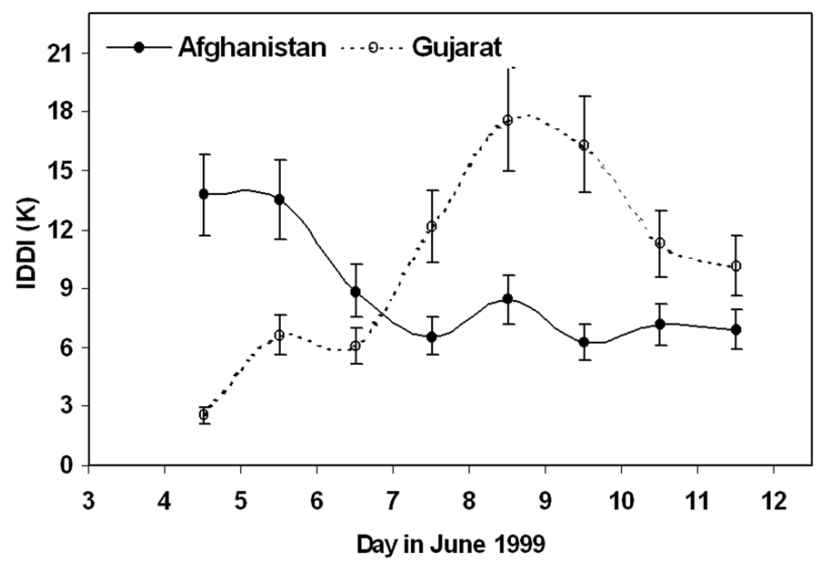

Fig. 18. Daily IDDI values (K) estimated over Afghanistan and Gujarat during a dust event.

the Indian deserts (Fig. 10). December was characterised by low IDDI values (Fig. 19) all over the study region.

\subsection{Difference between 1999 and 2003 dust episodes}

Using METEOSAT IR radiance, IDDI images were constructed for all days of 1999 and 2003. A comparison between 1999 and 2003 was made. The METEOSAT-5 was moved to the Indian Ocean region by the end of 1998. Since full year data were available in 1999, we have used 1999 data to study dust aerosols. We have compared these results with 2003, since 2003 was a year with alarge number of dust storms based on meteorological department reports based on visibility data.

Using daily noon-time IDDI images monthly mean images were constructed. Since various regions act as a dust source during different seasons, temporal variations of dust at various regions were studied separately. We examine the seasonal variations in dust in the following seven regions, which include both dry and vegetated (and moist) regions. Since dust spatial distribution is highly uneven, we have selected small regions (typically $5^{\circ} \times 5^{\circ}$ boxes).

These seven regions are:

1. Arabian Desert-I (Saudi Arabia-I) $\left(19^{\circ} \mathrm{N}-24^{\circ} \mathrm{N}\right.$ and $\left.53^{\circ} \mathrm{E}-58^{\circ} \mathrm{E}\right)$

2. Arabian Desert-II (Saudi Arabia-II) $\left(19^{\circ} \mathrm{N}-24^{\circ} \mathrm{N}\right.$ and $\left.45^{\circ} \mathrm{E}-50^{\circ} \mathrm{E}\right)$

3. Northeast (NE) Africa $\left(5^{\circ}-10^{\circ} \mathrm{N}\right.$ and $\left.35^{\circ} \mathrm{E}-40^{\circ} \mathrm{E}\right)$

4. Somalia $\left(5^{\circ}-10^{\circ} \mathrm{N}\right.$ and $\left.43^{\circ} \mathrm{E}-48^{\circ} \mathrm{E}\right)$

5. Indian Desert (Rajasthan) $\left(25^{\circ} \mathrm{N}-30^{\circ} \mathrm{N}\right.$ and $70^{\circ} \mathrm{E}-$ $76^{\circ}$ E) (North West India)

6. Gujarat $\left(21^{\circ} \mathrm{N}-25^{\circ} \mathrm{N}\right.$ and $\left.68^{\circ} \mathrm{E}-74^{\circ} \mathrm{E}\right)$ (Northwest India)

7. Central India $\left(20^{\circ} \mathrm{N}-25^{\circ} \mathrm{N}\right.$ and $\left.75^{\circ} \mathrm{N}-85^{\circ} \mathrm{E}\right)$. 

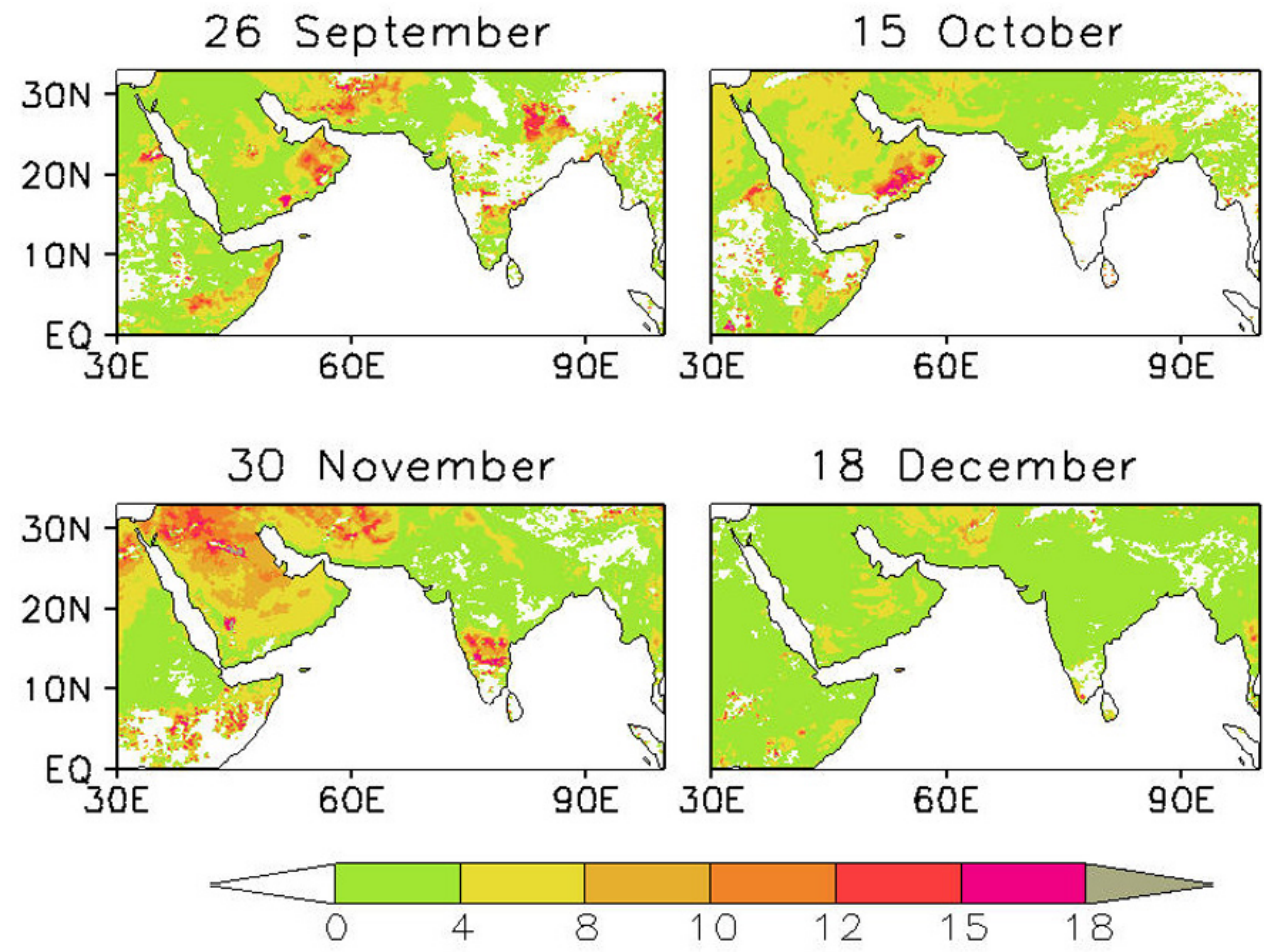

Fig. 19. Typical examples of regional distribution of IDDI (K) during September, October, November and December.

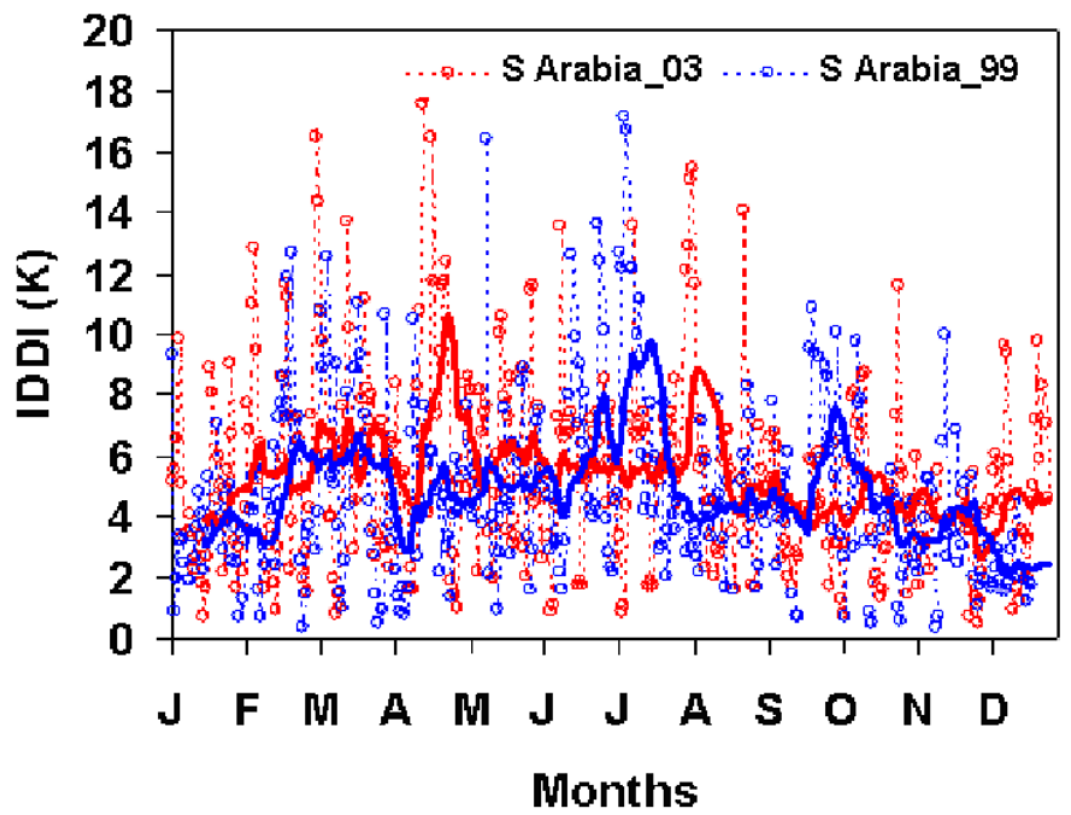

Fig. 20. Temporal Variation of IDDI (K) (dashed lines) for 1999 (blue) and 2003 (red) over the Saudi Arabian Desert $\left(53^{\circ} \mathrm{N}-58^{\circ} \mathrm{N}\right.$ and $\left.19^{\circ} \mathrm{E}-24^{\circ} \mathrm{E}\right)$. The solid lines represent a 15 -day running average.

The boundaries of these regions are marked in Fig. 9 (vegetation index maps). Thus, three boxes represent dry (no vegetation) regions (Regions-1, 2 and 4 in Fig. 9), two boxes represent vegetated regions (Regions-3 and 7 in Fig. 9) and two partly vegetated region (Regions-5 and 6 in Fig. 9). The numbers inside the boxes represent various regions, which are used subsequently in the discussions to identify regions. 

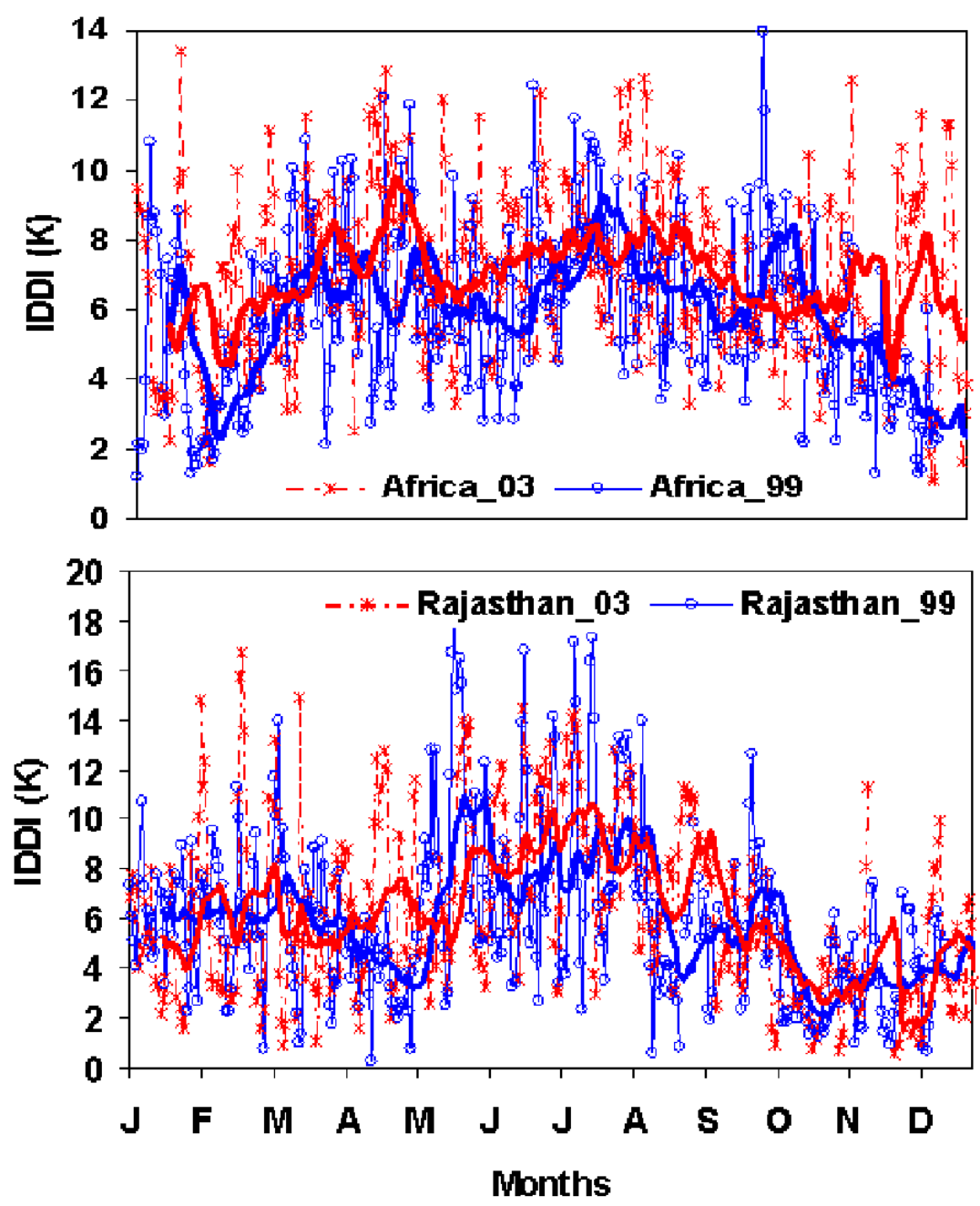

Fig. 21. Temporal variation of IDDI (K) (dashed lines) for 1999 (blue) and 2003 (red) over northeast Africa and Rajasthan. The solid lines represent a 15-day running average.

Figures 20 to 22 compare IDDI (daily values) in 1999 (blue) and 2003 (red), for five regions out of the seven considered. In Figs. 20 to 22, dashed lines correspond to daily values and the solid line represents the 15- day running average. It was observed that most of the regions show a general tendency in seasonal pattern in IDDI, with maximum values during the May to August period. It was also observed that for NE Africa a period of maximum IDDI is difficult to define. On a monthly or annual scale IDDI was higher in 2003 by $2 \mathrm{~K}$ (Tables 2 and 3). Another feature observed in all regions was the high day-to-day variability in dust load. Quantitative comparison of IDDI between 1999 and 2003 is given in Tables 2 and 3. These tables provide comparison for Saudi Arabia-II and Somalia, which are not shown in Figs. 20 to 22. Tables 4 and 5 provide information on the maximum daily IDDI within each month.

Figure 20 shows the IDDI variation over the Arabian Desert (Saudi Arabia-I; Region-1 in Fig. 9) and it can be seen that during March-April, June-July and September-October IDDI reaches high values (in 1999), with the highest value of $\sim 18 \mathrm{~K}$ during April to July. Even in November few days show high IDDI, which could be due to short period dust events. An almost similar pattern was observed in 2003 but dust the load was slightly more, especially in April-May, August-September and December. The NE African region (excluding Somalia; Region-4 in Fig. 9) is not a dust source but it is adjacent to the Sahara and Sahel. This region shows the highest IDDI during April-May and August. As shown in the upper panel of Fig. 21, IDDI values for 2003 are slightly higher than that of 1999 (Table 3).

Another region considered was the "Thar Desert" in Northwest India, which extends over the northwest part of Rajasthan (locations defined earlier; Region-5 in Fig. 9). It receives very low annual rainfall and remains hot and dry during the daytime. The lower panel of Fig. 21 shows the variation of the dust load over this region. Average IDDI in this region is nearly $8 \mathrm{~K}$ throughout the year, but the region experienced a number of dust storms in May, June and July. As a consequence, IDDI often reaches as high as $19 \mathrm{~K}$ (representing a thick atmospheric dust layer). 

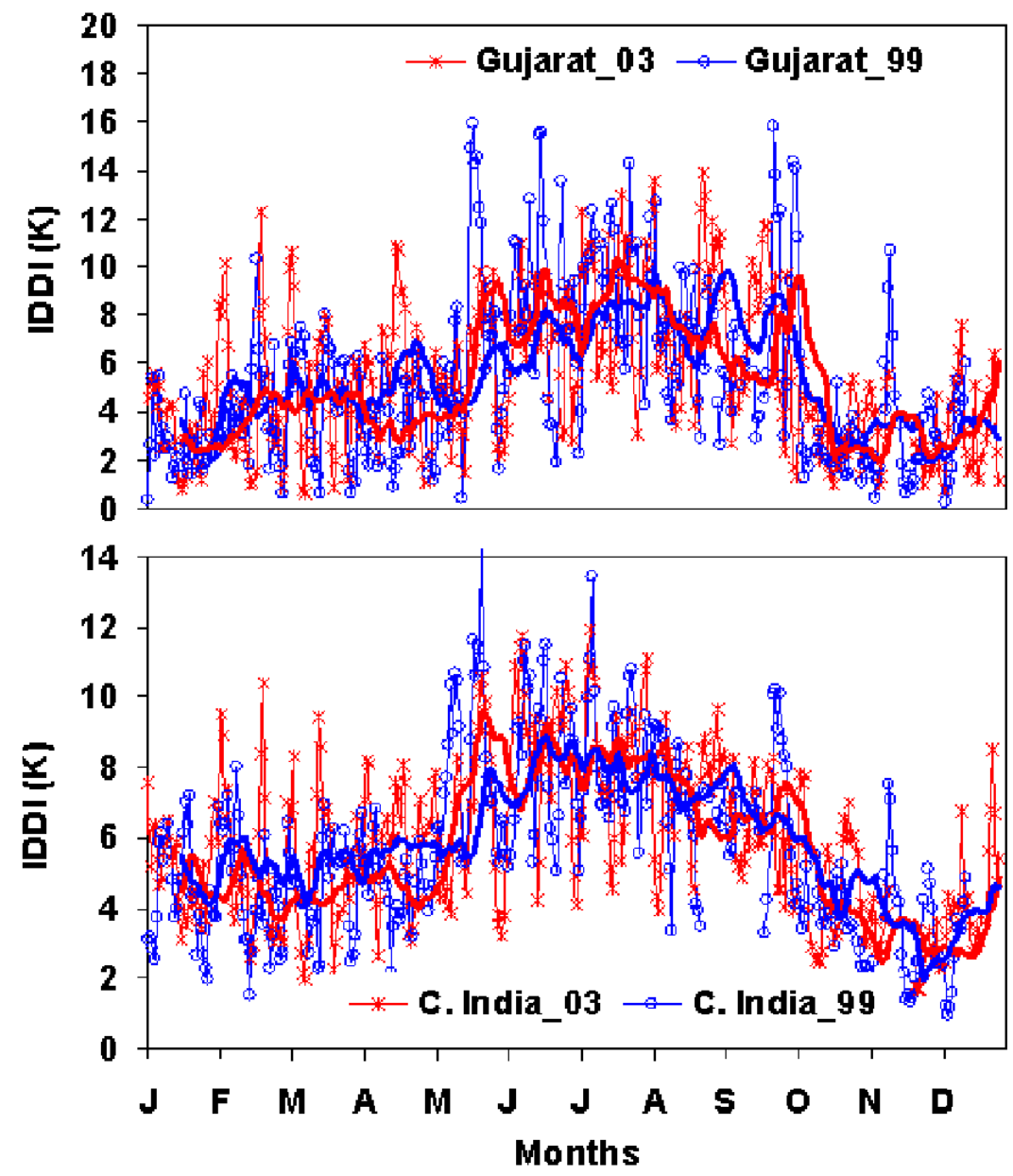

Fig. 22. Temporal variation of IDDI (K) (dashed lines) for 1999 (blue) and 2003 (red) over Gujarat and central India.

Over Gujarat (Region-6 in Fig. 9), the dust load increases in June, as shown in Fig. 22 (top panel), and the IDDI reaches a value as high as $16 \mathrm{~K}$. Again, in September and October high dust loading was observed. Central India (Region-7 in Fig. 9) can be considered as a vegetated region. The largest IDDI observed in this region was $\sim 13 \mathrm{~K}$. In summary, the dust load was, in general, maximum during the May to August period over most of the regions considered. The IDDI during this period was, on a monthly scale, higher in 2003 compared to 1999 (Tables 2, 3, 4 and 5).

Next, we consider the regional distribution of IDDI averaged over a month and show a comparison of 1999 and 2003. Figures 23 to 26 show a comparison of IDDI between 1999 and 2003 for the whole study area $\left(0-35^{\circ} \mathrm{N} ; 30^{\circ} \mathrm{E}-100^{\circ} \mathrm{E}\right)$. The number of days averaged per month was mostly 30 or 31. But during the monsoon months, the number of days varies from 20 to 28 (data unavailability due to cloudy sky conditions). Over the northern part of India, along the IndoGangetic plain, an interesting feature with high IDDI values ranging between $6-12 \mathrm{~K}$ was observed in both years. Other parts of India, Saudi Arabia and the NE African regions did not show any dust activity in January. High IDDI over North India disappears in February and only a few patches, indicating moderate dust load, were observed over central India, as well as Deccan Plateau of India, which gradually intensified in March. The large IDDI observed over the IndoGangetic plains was discussed in Sect. 4.2.1, in conjunction with Fig. 13. The band of large IDDI observed over the Indo-Gangetic plains, even on a monthly average scale (in January), indicates that this is a frequently occurring event.

In March, IDDI started increasing until July. During June and July high IDDI values were observed during 2003 over arid and semiarid regions of India and adjacent regions. During June, the Thar Desert of India experienced a large number of dust storms of various intensities, which resulted in a significantly high IDDI, with the highest value in July over NE Africa. However, the Arabian Desert had the highest IDDI in March (which was concentrated over the central part of Arabia). The IDDI was low in April 2003 but it appears that dust was spread all over the Arabian region. In July 2003, a part of the Arabian region experienced a high dust load that slowly reduced in August. It is important to note that the difference 


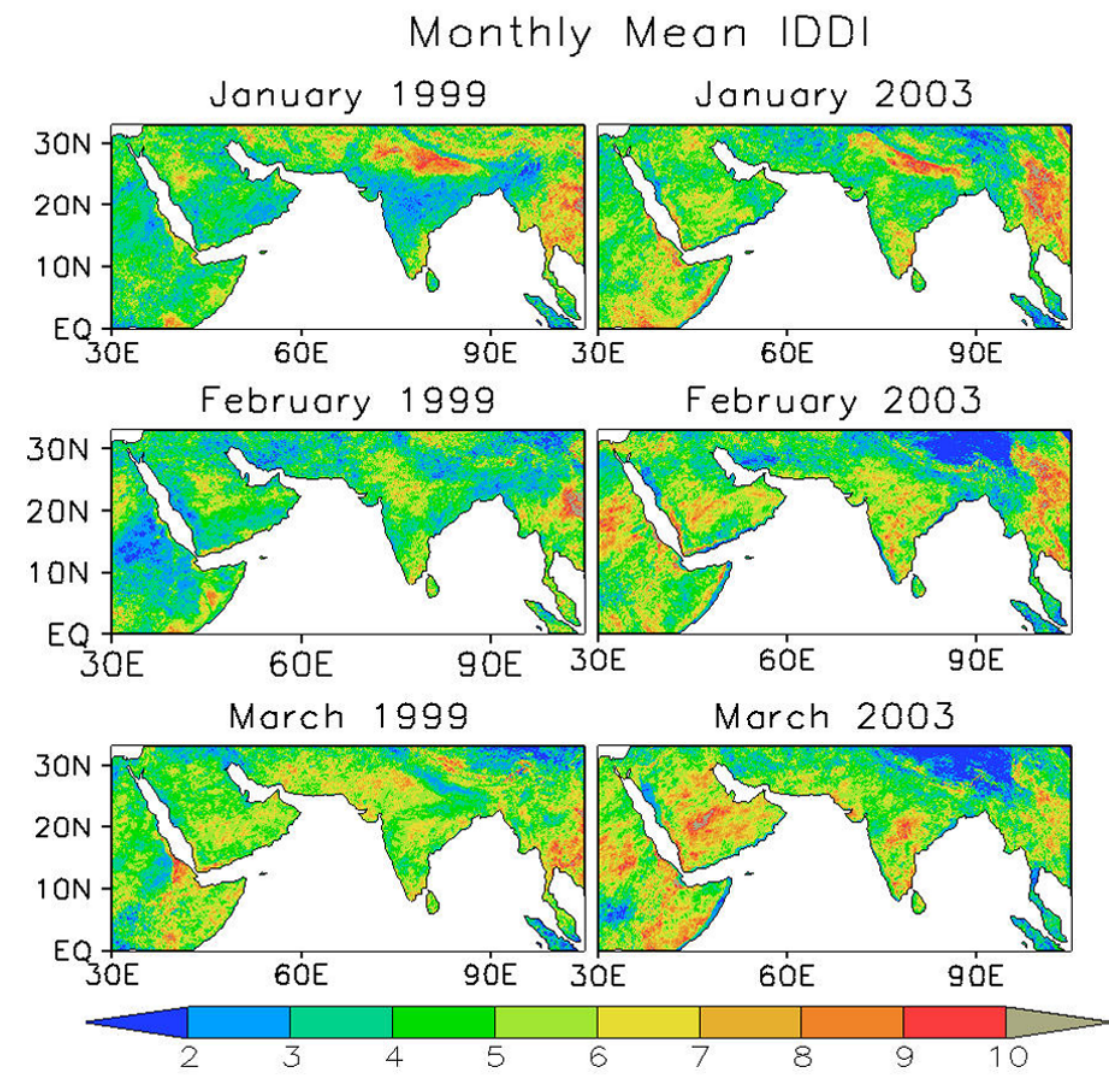

Fig. 23. Regional distribution of IDDI (K) for January, February and March (1999 and 2003).

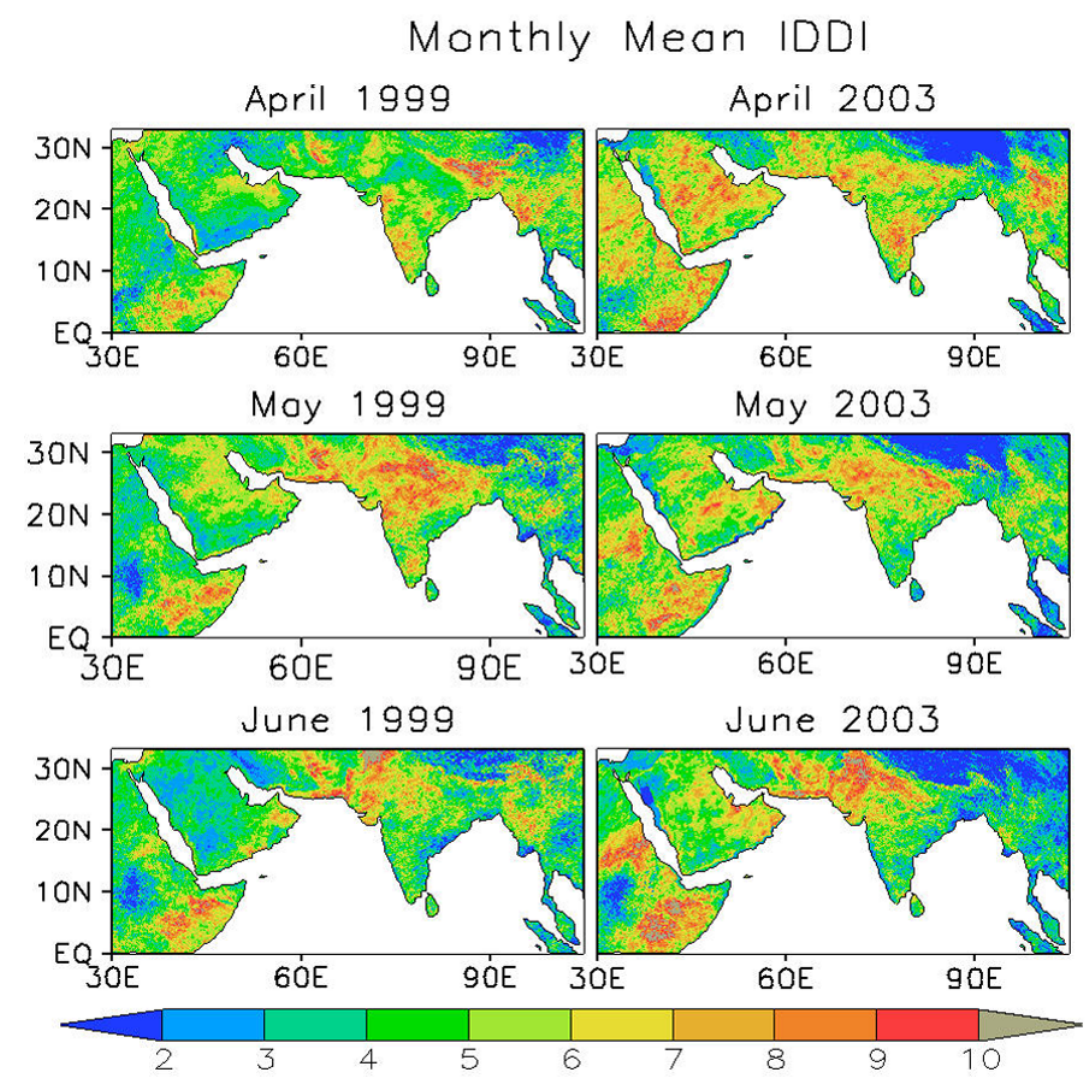

Fig. 24. Regional distribution of IDDI (K) for April, May and June (1999 and 2003). 
Monthly Mean IDDI
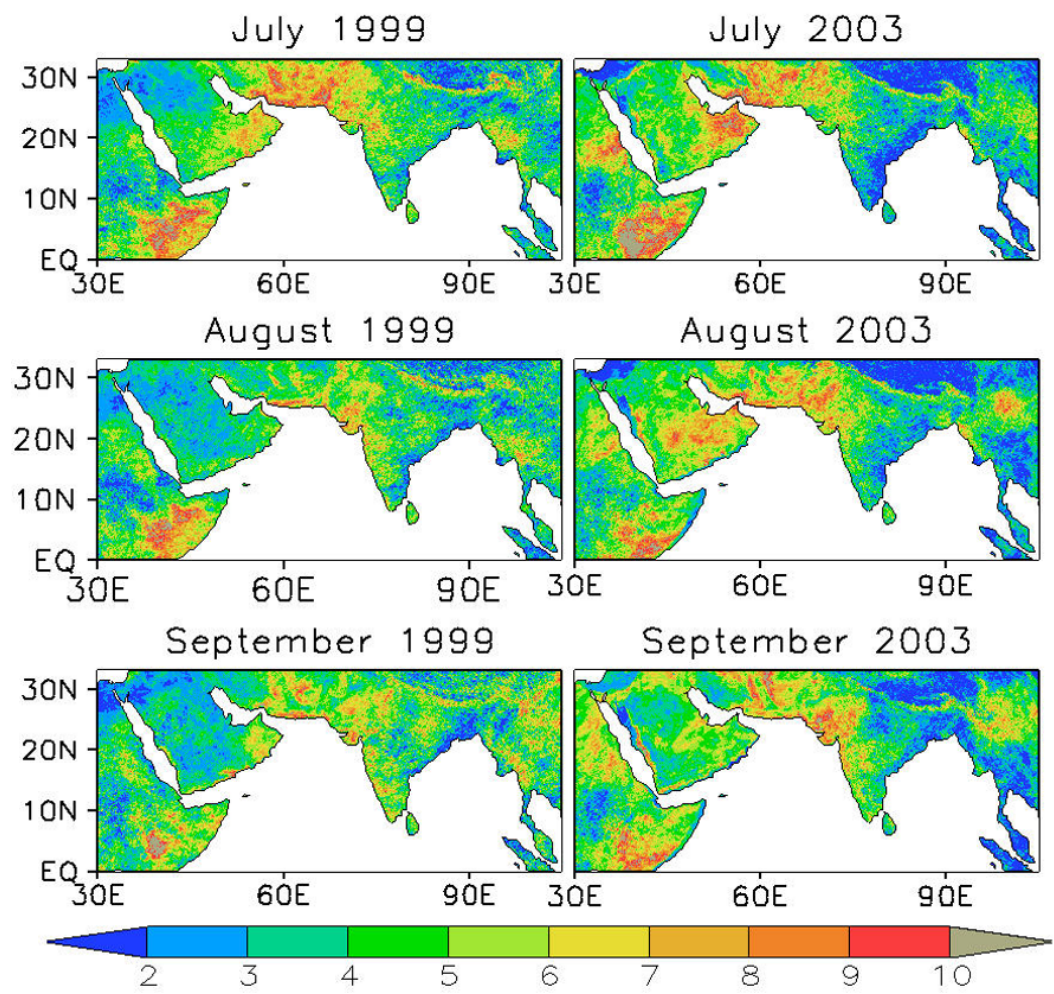

Fig. 25. Regional distribution of IDDI (K) for July, August and September (1999 and 2003).

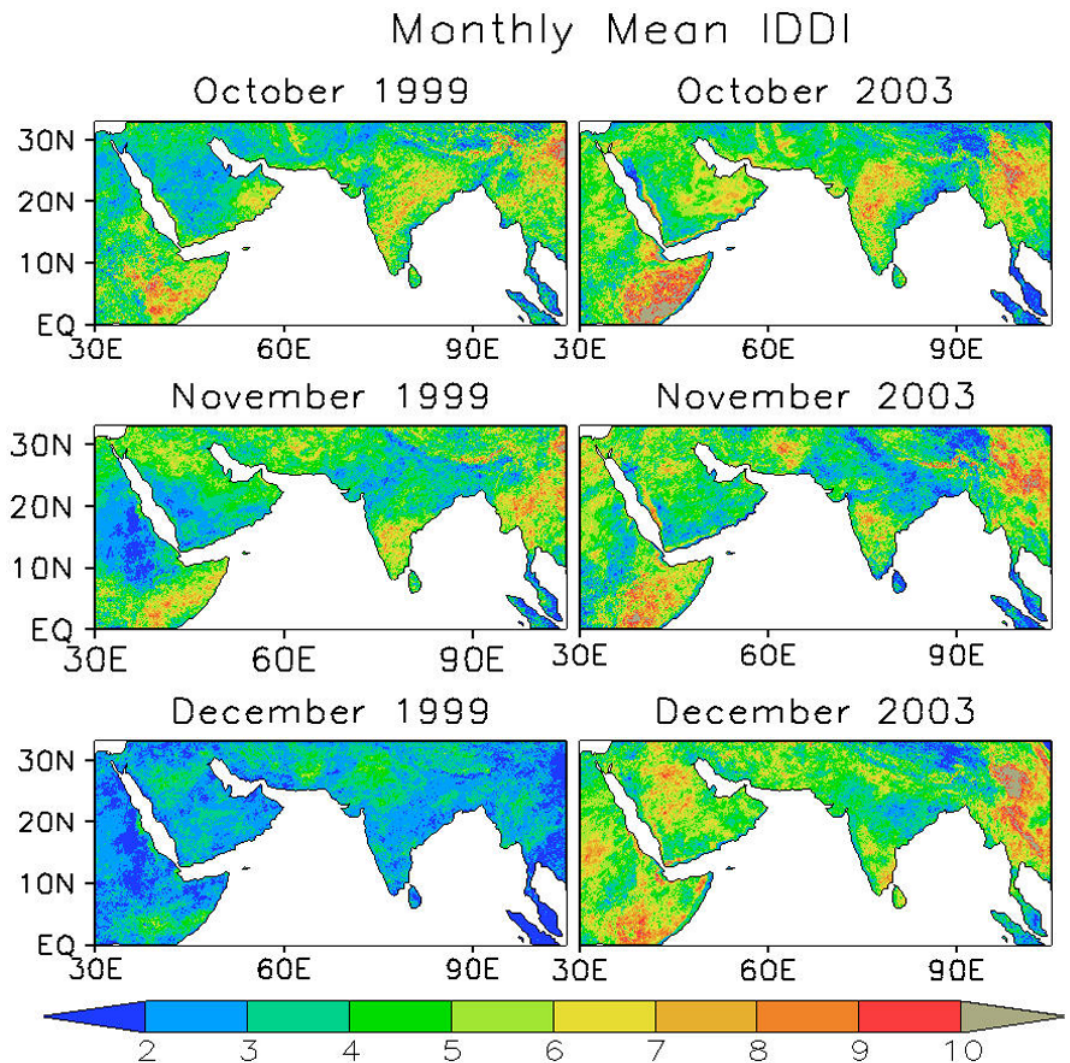

Fig. 26. Regional distribution of IDDI (K) for October, November and December (1999 and 2003). 
in IDDI distribution (between 1999 and 2003) was dramatic in December and that IDDI values were drastically higher in 2003. In Part II, we make an effort to quantify wind dependence of IDDI and estimate the radiative effects of dust.

\section{Conclusions}

1. Spatial and temporal variability in dust loading over arid and semiarid regions of India and adjacent continents (excluding Sahara) are studied.

2. It was observed that dust activity starts by March over the Indian deserts, as well as over the deserts of Africa and the Arabian regions and reaches maximum during May to August.

3. Large day-to-day variation in IDDI was observed over the entire study region with values ranging from 4 to 22 .

4. During the dry season, the magnitude of the monthly average IDDI during 2003 was slightly higher than that of 1999 .

5. Monthly mean IDDI was in the range from 4 to 9 over the Indian deserts, as well as over the deserts of Africa. The maximum IDDI during a month was as high as in the range from 6 to 18 .

6. Large IDDI values were observed even over vegetated regions (such as the vegetated part of Africa and central India), attributed to the presence of transported dust from nearby deserts.

7. Regional maps of IDDI, in conjunction with biomass burning episodes (using TERRA satellite fire pixel counts), suggest that large IDDI values observed during the winter months over Northern India could be due to a possible deposition of black carbon on larger dust aerosols.

Acknowledgements. The authors thank Department of Science and Technology, New Delhi for supporting this work. We also thank LMD and EUMETSAT for providing METEOSAT-5 data and NCEP/NCAR for providing wind and soil moisture data. We sincerely thank the anonymous referees for their valuable suggestions, which has improved the quality of the paper substantially.

Topical Editor O. Boucher thanks three referees for their help in evaluating this paper.

\section{References}

Ackerman, S. A.: Using the radiative temperature difference at 3.7 and $11 \mu \mathrm{m}$ to track dust outbreaks, Remote Sens. Environ., 27, 129-133, 1989.

Alpert, P., Kaufman, Y. J., Shay-El, Y., et al.: Quantification of dustforced heating of the lower troposphere, Nature, 395, 367-370, 1998.

Arimoto, R., Duce, R. A., Ray, B. J., et al.: Trace elements in the atmosphere over the north Atlantic, J. Geophys. Res., 100, 1199$1213,1995$.
Arimoto, R., Ray, B. J., Lewis, N. F., et al.: Mass-particle size distributions of atmospheric dust and the dry deposition of dust to the remote ocean, J. Geophys. Res., 102, 15 867-15 874, 1997.

Arimoto, R: Eolian dust and climate: relationships to sources, tropospheric chemistry, transport and deposition, EarthScience Reviews, 54 (1-3), 29-42, 2001.

Brooks, N. and Legrand, M.: Dust variability over northern Africa and rainfall in the Sahel, in: Linking Land Surface change to climate change, edited by: McLaren, S. J. and Kniveton, D., Kluwer Academic Publishers, 1999.

Brooks, N.: Dust-climate interactions in the Sahel-Sahara zone of northern Africa, with particular reference to late twentieth century Sahelian drought, PhD Thesis, Climatic Research Unit, University of East Anglia, Norwich, 2000.

Chandra, S., Satheesh, S. K., and Srinivasan, J: Can the state of mixing of black carbon aerosols explain the mystery of "excess" atmospheric absorption?, Geophys. Res. Lett., 31, doi:10.1029/2004GL020662, 2004.

Chen, S.-J., Kuo, Y.-H., Ming, W., and Ying, H.: The effect of dust radiative heating on low-level frontogenesis, J. Atmos. Sci., 9, 1414-1420, 1995.

Christopher, S. A., Legrand, M., Marticorena, B., et al.: Estimation of diurnal short wave dust aerosol radiative forcing during PRIDE, J. Geophys. Res., 108 (D19): art. no. 8596, 2003.

Coackley, J. A. and Bretherton, F. P.: Cloud cover from highresolution scanner data: method and preliminary results, J. Geophys. Res., 87, 4917-4932, 1982.

d'Almeida, G. A., Koepke, P., and Shettle, E. P.: Atmospheric Aerosols-Global Climatology and Radiative Characteristics, A. Deepak, Hampton, VA, 1991.

Deepshikha, S., Satheesh, S. K., and Srinivasan, J.: Regional Distribution of Absorbing Efficiency of Dust Aerosols over India and Adjacent Continents inferred using Satellite Remote Sensing, Geophys. Res. Lett., 32 (3), art. no. L03811, 2005.

Gillette, D. A.: Environmental factors affecting dust emissions by wind erosion, Saharan Dust, C. Morales, Ed., Wiley, 71-94, 1979.

Ginoux, P., Chin, M., Tegen, I., Prospero, J. M., Holben, B., Dubovik, O., and Lin, S.J.: Sources and distributions of dust aerosols simulated with the GOCART model, J. Geophys. Res., 106 (D17), 20 255-20 273, 2001.

Ginoux, P., Prospero, J. M., Torres, O., and Chin, M.: Long-term simulation of dust distribution with the GOCART model: Correlation with the North Atlantic Oscillation, Environmental Modeling and Software, 19, 113-128, 2004.

Girolamo, Di. L., Bond, T. C., Bramer, D., et al.: Analysis of Multiangle Imaging SpectroRadiometer (MISR) aerosol optical depths over greater India during winter 2001-2004, Geophys. Res. Lett., 31, L23115, doi:10.1029/2004GL021273, 2004.

Gong, S. L., Zhang, X. Y., Zhao, T. L., McKendry, I. G., Jaffe, D. A., and Lu, N. M.: Characterization of soil dust aerosol in China and its transport and distribution during 2001 ACEAsia: 2. Model simulation and validation, J. Geophys. Res., 108, doi:10.1029/2002JD002633, 2003.

Haywood, J. and Boucher, O.:, Estimates of the direct and indirect radiative forcing due to tropospheric aerosols: A review, Rev. Geophys., 38 (4), 513-543, 2000.

Haywood, J. M., Francis, P. N., Glew, M. D., and Taylor, J. P.: Optical properties and direct radiative effect of Saharan dust: A case study of two Saharan dust outbreaks using aircraft data, J. Geophys. Res., 106 , D16, 18 417, doi:10.1029/2000JD900319, 2001. 
Haywood, J., Francis, P., Osborne, S., Glew, M., Loeb, N., Highwood, E., Tanré, D., Myhre, G., Formenti, P., and Hirst, E.: Radiative properties and direct radiative effect of Saharan dust measured by the C-130 aircraft during SHADE: 1 . Solar spectrum, J. Geophys. Res., 108(D18), 8577, doi:10.1029/2002JD002687, 2003.

Heintzenberg, J. R., Charlson, R. J., Clarke, A. D., Liousse, C., Ramaswamy, V., Shine, K. P., and Wendisch, M.: Measurement and modeling of aerosol singlre scattering albedo: Progress, problems and prospects, Contrib. Atmos, Phys., 70, 249-264, 1997.

Helgren, D. A. and Prospero, J. M.: Wind velocities associated with dust deflation events in the western Sahara, J. Climate Applied Meteorol., 26, 1147-1151, 1987.

Hess, M., Koepke, P., and Schult, I.: Optical properties of aerosols and clouds: The software package OPAC, Bulletin of Am. Meteorol. Soc., 79, 831-844, 1998.

Holben, B. N., Eck, T. F., Slutsker, I., et al.: AERONET-A federated instrument network and data archive for aerosol characterization, Remote Sens. Environ., 66, 1-16, 1998.

Hsu, N. C., Tsay, S. C., King, M. D., et al.:Aerosol properties over bright-reflecting source regions, IEEE Trans. Geosci. Rem. Sens., 42(3), 557-569, 2004.

Intergovernmental Panel on Climate Change, Climate Change 1994: Radiative Forcing of Climate, report to IPCC from the Scientific assessment Group (WGI), Cambridge Univ. Press, New York, 2001.

Jacobson, M. Z.: Strong Radiative heating due to the mixing state of black carbon in atmospheric aerosols. Nature, 409, 695-697, 2001.

Jaenicke, R.: Natural aerosols, Annuals of the New York Academy of Science, 317-329, 1980.

Jaenicke, R.: Tropospheric aerosols. in: Aerosol-Cloud-Climate Interactions, edited by: Hobbs, P. V., Academic Press, NewYork, 1-31, 1993.

Junge C. E.: Our knowledge of the Physico-Chemistry of aerosols in the undisturbed marine environment, J. Geophys. Res., 77, 5183-5200, 1972.

Kalu, A. E.: The African dust plume: its characteristics and propagation across West Africa in winter, in: Saharan Dust: Mobilisation, transport, deposition: papers and recommendations from a workshop held in Gothenburg, Sweden, 25-28 April 1977, edited by: Morales, C., Wiley, 1979.

Kaufman, Y. J.: Remote sensing of direct and indirect aerosol forcing, in: Aerosol Forcing of Climate: Report of the Dahlem Workshop on Aerosol Forcing of Climate, Berlin 1994, April 24-29, edited by: Charlson, R. J. and Heintzenberg, J., 297-332, 1995.

Kaufman, Y. J., Tanré, D., Gordon, H. R., et al.: Passive remote sensing of tropospheric aerosol and atmospheric correction for the aerosol effect, J. Geophys. Res., 102 (D14), 16815-16830, 1997.

Kaufman, Y. J., Tanré, D., Dubovik, O., et al.: Absorption of sunlight by dust as inferred from satellite and ground-based remote sensing, Geophys. Res. Lett., 28 , 1479-1483, 2001.

Kaufman, Y. J., Tanré, D., and Boucher, O.: A satellite view of aerosols in the climate system, Nature, 419 (6903), 215-223, 2002.

Lacis, A. A. and Mishchenko, M. I.: Climate forcing, climate sensitivity, and climate response: a radiative modeling perspective on atmospheric aerosols, in: Aerosol Forcing of Climate: Report of the Dahlem Workshop on Aerosol Forcing of Climate, Berlin 1994, April 24-29, edited by: Charlson, R. J. and Heintzenberg, J. 11-42, 1995.
Legrand, M. : Etude des brumes seches sur I'Afrique de I'Quest a l'aide de Meteosat-I, Meteorology, VI, 29-30, 153-159, 1983.

Legrand, M.: Dust clouds over west Africa: A characterization by satellite data, Ann. Geophys., 3, 777-784, 1985.

Legrand, M.: The potential of infrared satellite data for the retrieval of Saharan-dust optical depth over Africa, J. Appl. Meteorol., 28, 309-319, 1989.

Legrand, M.: Thermal impact of Saharan dust over land, Part-II, Application to satellite IR remote sensing, J. Appl. Meteorol., 31, 181-193, 1992.

Legrand, M., N'Doume, C., and Jankowiak, I.: Satellite-derived climatology of the Saharan aerosol, Passive Infrared remote sensing of clouds and the atmosphere II, edited by: Lynch, D. K., Proc. SPIE 2309, 127-135, 1994.

Legrand, M., Plana-Fattori, A., and N'doume, C. : Satellite detection of dust using the IR imagery of Meteosat 1. Infrared difference dust index, J. Geophys. Res., 106 (D16), 18 251-18 274, 2001.

Leon, F. and Legrand, M.: Mineral dust sources in the surroundings of the north Indian Ocean, Geophys. Res. Lett., 30, 1309, doi:10.1029/2002GL016690, 2003.

Li, X., Maring, H., Savoie, D., Voss, K., and Prospero, J. M.: Dominance of Mineral Dust in Aerosol light-scattering in the North Atlantic Trade Winds, Nature, 380, 416-422, 1996.

Li, F., Vogelmann, A. M., and Ramanathan, V.: Saharan dust aerosol radiative forcing measured from space, J. Climate, 17 (13), 2558-2571, 2004.

Liao, H. and Seinfeld, J. H.: Radiative forcing by mineral dust aerosols: sensitivity to key variables, J. Geophys. Res., 103, 31 637-31 645, 1998.

Maley, J.: Dust, clouds, rain types, and climatic variations in tropical North Africa, Quaternary Research, 18, 1-16, 1982.

Martonchik, J. V.: Comparison of MISR and AERONET aerosol optical depths over desert sites, Geophys. Res. Lett., 31 (16), art. no. L16102, 2004.

McTainsh, G. H.: Harmattan dust deposition in northern Nigeria, Nature, 286, 587-588, 1980.

Miller, R. L. and Tegen I.: Radiative forcing of a tropical direct circulation by soil dust aerosols, J. Atmos. Sci., 56 (14), 2403 2433, 1999.

Miller, R. L., Tegen, I., and Perlwitz, J.: Surface radiative forcing by soil dust aerosols and the hydrologic cycle, J. Geophys. Res., 109 (D4), art. no. D04203, 2004.

Mohalfi, S., Bedi, H. S., and Krishnamurti, T. N.: Impact of short wave radiative effects of dust aerosols on the summer season heat low over Saudi Arabia, Monthly Weather Rev., 126, 3153-3168, 1998.

Moorthy, K. K., Sunilkumar, S. V., Pillai, P. S., et al.: Wintertime spatial characteristics of boundary layer aerosols over peninsular India, J. Geophys. Res., 110 (D8), art. no. D08207, doi:10.1029/2004JD005520, 1-11, 2005.

Moulin, C., Lambert, C. E., and Dayan, U., et al.: Satellite climatology of African dust transport in the Mediterranean atmosphere, J. Geophys. Res., 103, 13 137-13 143, 1998.

Nickling, W. G. and Gillies, J. A.: Emission of dust from desert soils, in: Paleoclimatology and Paleometeorology: Modern and Past Patterns of Global Atmospheric Transport, edited by: Leinen, M. and Sarnthein, M., 133-165, Kluwer, 1989.

N'Tchayi, M. G., Bertrand, J. J., and Nicholson, S. E.: The diurnal and seasonal cycles of wind-borne dust over Africa north of the equator, J. Appl. Meteorol. 36, 868-882, 1997.

Parungo, F. P. : Marine aerosols in the marine aerosols in the marine 
upwelling regions, J. Aerosol Science, 18, 277-290, 1987.

Petit, R. H., Legrand, M., Jankowiak, I., et al.: Transport of Saharan dust over the Caribbean islands: study of an event, J. Geophys. Res., 110 (D18), art. no. D18S09, 1-9, 2005.

Prospero, J. M., Charlson, R. J., Mohnen, V., Jaenicke, R., Delany, A. C., Moyers, J., Zoller, W., and Rahn, K.: The atmospheric aerosol system - an overview, Rev. Geophys. Space Phys., 21, 1607-1629, 1983.

Prospero, J. M.: African dust in America, Geotimes, 46 (11), 24 27, 2001.

Prospero, J. M., Ginoux, P., Torres, O., et al.: Environmental characterization of global sources of atmospheric soil dust identified with the Nimbus 7 Total Ozone Mapping Spectrometer (TOMS) absorbing aerosol product, Rev. Geophys., (1), art. no. 1002 AUG-SEP, 1-22, 2002.

Prospero, J. M.: Global dust transport over the oceans: The link to climate, Geochimica Et Cosmochimica Acta, 67 (18), A384A384 Supp., 2003.

Prospero, J. M. and Lamb, P. J.: African droughts and dust transport to the Caribbean: Climate change implications, Science, 302 (5647), 1024-1027, 2003.

Satheesh S. K. and Ramanathan, V.: Large differences in tropical aerosol forcing at the top of the atmosphere and earth's surface, Nature, 405, 60-63, 2000.

Satheesh, S. K., and Srinivasan, J.: Enhanced aerosol loading over Arabian Sea during pre-monsoon season: Natural or Anthropogenic?, Geophys. Res. Lett., doi:10.1029/2002GL015687, 2002 .

Satheesh, S. K and Moorthy, K. K.: Radiative Effects of natural Aerosols, Atmospheric Environment, 39, 2089-2110, 2005.

Satheesh, S. K., Krishna Moorthy, K., Kaufman Y. J., et al.: Aerosol Optical Depth, Physical Properties and Radiative Forcing over the Arabian Sea, Meteorol. Atmos. Phys., April, 45-62, 2005.

Schollaert, S. E. and Merrill, J. T.: Cooler seas surface west of the Sahara Desert correlated to dust events, Geophys. Res. Lett., 25 (18), 3529-3532, 1998.

Seinfeld, J. H., Carmichael, G. R., Arimoto, R., et al.: Regional Climatic and Atmospheric Chemical Effects of Asian Dust and Pollution, Bull. Amer. Meteorol. Soc., 367-380, 2004.

Shaw, G. E.: Transport of Asian desert Aerosol to the Hawaiian Islands, J. Appl. Meteorol., 19, 1254-1259, 1980.
Shaw, G. E., Benner, R. L., Cantrell, W., et al.: The regulation of climate: A sulfate particle feedback loop involving deep convection - An editorial essay, Climate Change, 39 (1), 23-33, 1998.

Shenk, W. E., and Curran, R. J.: The detection of dust storms over land and water with satellite visible and infrared measurements, Mon. Weather rev., 102, 830-837, 1974.

Sokolik, I. N., Toon, O. B., and Bergstrom, R. W.: Modeling the radiative characteristics of airborne mineral aerosols at infrared wavelengths, J. Geophys. Res., 103 (D8), 8813-8826, 1998.

Tanré, D. and Legrand, M.: On the satellite retrieval of Saharan dust optical thickness over land: Two different approaches, J. Geophys. Res., 96, 5221-5227, 1991.

Tanré, D., Kaufman, Y. J., and Holben, B. N.: Climatology of dust aerosol size distribution and optical properties derived from remotely sensed data in the solar spectrum, J. Geophys. Res., 106(D16), 18 205-1 8217, 2001.

Tanré, D., Haywood, J., Pelon, J., et al.: Measurement and modeling of the Saharan dust radiative impact: Overview of the Saharan Dust Experiment (SHADE), J. Geophys. Res., 108(D18), 8574, doi:10.1029/2002JD003273, 2003.

Tegen, I. and Fung, I.: Modelling of Mineral Dust in the Atmosphere: Sources, Transport, and Optical Thickness, J. Geophys. Res., 99, 22 897-22 914, 1994.

Tegen, I. and Miller, R. A.: general circulation model study on the inter-annual variability of soil dust aerosol, J. Geophys. Res., 103 (D20), 25 975-2 5995, 1998.

Tegen, I., Werner, M., Harrison, S. P., and Kohfeld, K. E.: Relative importance of climate and land use in determining present and future global soil dust emission, Geophys. Res. Lett., 31, L05105, doi:10.1029/2003GL019216, 2004.

Tripathi, S. N., Dey, S., Tare, V. and Satheesh S. K.: Aerosol black carbon radiative forcing at an industrial city in northern India, Geophys. Res. Lett., 32 (8), art. no. L08802, 1-4, 2005.

Zender, C. S., Bian, H., and Newman, D.: Mineral Dust Entrainment and Deposition (DEAD) model: Description and 1990s dust climatology, J. Geophys. Res., 108(D14), 4416, doi:10.1029/2002JD002775, 2003.

Zhang, J. L. and Christopher, S. A.: Long wave radiative forcing of Saharan dust aerosols estimated from MODIS, MISR, and CERES observations on Terra, Geoephys. Res. Lett., 30 (23), art. no. 2188, 1-4, 2003. 